\title{
Bicycle \& Pedestrian Infrastructure Improvements Realized in Communities of Less Than 10,000 People: \\ Final Report
}

\author{
by \\ Natalie Villwock-Witte \\ Assistant Research Professor/Research Engineer \\ Western Transportation Institute \\ College of Engineering \\ Montana State University \\ A report prepared for the \\ Maine Department of Transportation \\ Minnesota Department of Transportation \\ New Hampshire Department of Transportation
}

December 14, 2018 


\title{
DISCLAIMER
}

The contents of this report reflect the views of the authors, who are responsible for the facts and the accuracy of the information presented herein. This document is disseminated in the interest of information exchange. The report is funded, partially or entirely, by a grant from the U.S. Department of Transportation's University Transportation Centers Program. However, the U.S. Government assumes no liability for the contents or use thereof.

\begin{abstract}
AVAILABILITY OF DATASET
To encourage detailed and candid opinions, survey (interview) respondents were promised anonymity. Further, given the small number of total respondents to the survey, it may have been possible to match responses to specific communities and/or individuals. Therefore, due to these unique research conditions, a final dataset with complete survey results is not publicly available.
\end{abstract}




\section{ACKNOWLEDGEMENTS}

The author would like to acknowledge the importance of the participation by community members - without them, this project would not be possible. The author would like to acknowledge the recommended contacts provided by the Maine, Minnesota and New Hampshire State Departments of Transportation stakeholders. The author would like to recognize the insight and suggestions provided by Patrick Adams and Dale Peabody of the Maine Department of Transportation; Renee Raduenz, Sara Dunlap and Janette Kihm of the Minnesota Department of Transportation; Erik Paddleford of the New Hampshire Department of Transportation; Craig Tufts of the Central New Hampshire Regional Planning Commission; and Mari Brunner formerly of the Southwest Region Planning Commission. Finally, the author would like to acknowledge the technical editing provided by Carla Little, and the development of the maps by Karalyn Clouser, both of the Western Transportation of Institute, Montana State University. 


\section{TABLE OF CONTENTS}

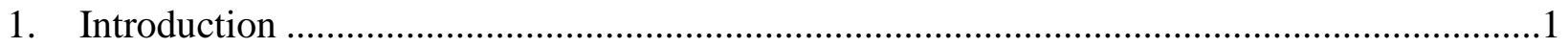

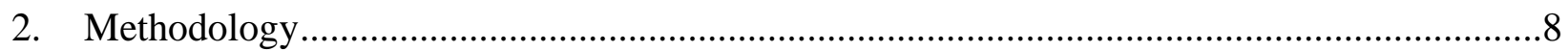

3. Literature Review \& Information Gathering .................................................................

4. Summary of Existing Dataset Findings .........................................................................12

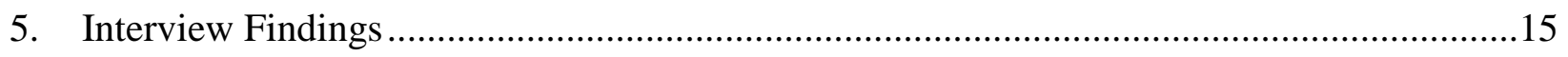

5.1. Characteristics That Impact Implementation ........................................................ 15

5.2. Infrastructure Implemented, Funding, Barriers, Wish List, \& Recommendations ........ 18

6. Interviews Compared with Literature Findings ..........................................................20

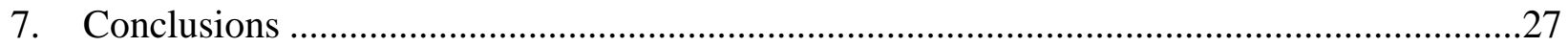

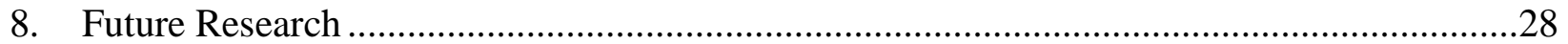

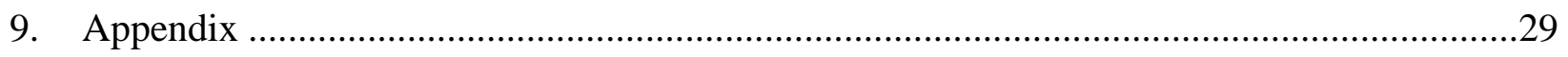

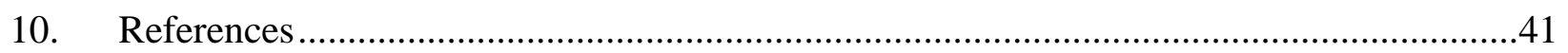




\section{LIST OF TABLES}

Table 1: Interviewed Communities............................................................................................. 1

Table 2: Interviews Administered, by Community...................................................................... 6

Table 3: Number of Communities with Less Than 10,000 People in Maine, Minnesota \& New

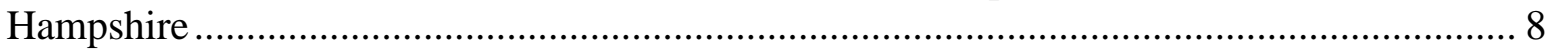

Table 4: LAB State Ranking, Number of Bicycle Friendly Communities within Stakeholder States, Number of Bicycle Friendly Businesses, Number of Bicycle Friendly Universities ............ 11 


\section{LIST OF FIGURES}

Figure 1: Communities within Maine ................................................................................ 2

Figure 2: Communities within Minnesota ……………….................................................... 3

Figure 3: Communities within New Hampshire ……………………..................................... 4

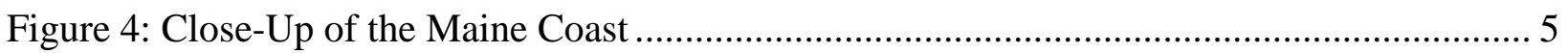




\section{EXECUTIVE SUMMARY}

The objective of this study was to better define underlying factors that have allowed communities of less than 10,000 people within three states (Maine, Minnesota, and New Hampshire) to successfully implement bicycle and pedestrian infrastructure. These factors were defined by first conducting a thorough literature review along with general information gathering, as there is little published knowledge about communities of less than 10,000 people. Based on the information collected and synthesized from the literature review, interview questions were developed to ask leadership (planners, town administrators, elected officials) and advocates within communities of less than 10,000 people. Interviewees were targeted from two types of communities: those that have successfully implemented bicycle and pedestrian infrastructure, and those that have shown potential to implement bicycle and pedestrian infrastructure. As an outcome of a series of in-depth interviews with key members in chosen communities, the following characteristics surfaced as being influential in whether or not bicycle and pedestrian infrastructure can be found within these smaller communities within Maine, Minnesota, and New Hampshire:

- The speed limits, particularly adherence to speed limits within a community,

- Having many champions for bicycle and pedestrian modes,

- Having programs to teach or support bicycle and/or pedestrian modes,

- Having bicycle and/or pedestrian groups, and

- The community approval process.

The following characteristics were not found to influence whether or not bicycle and pedestrian infrastructure can be found within a community of less than 10,000 people:

- Population growth or decline,

- Presence of an institution of higher education,

- Identification as a tourist destination,

- Identification as a historic or preservation district,

- Description of bicycle and pedestrian modes as transportation,

- Land use within the community,

- Events hosted with road closures,

- Presence of neighborhood groups, and

- Familiarity by leadership and advocates with bicycle and pedestrian infrastructure.

This research project provides informative, foundational information on which future initiatives on related topics can build. 


\section{INTRODUCTION}

Walking and bicycling have become increasingly popular transportation modes as people more and more consider the positive impacts of active living and the negative impacts (e.g., environmental and health) of a society solely dependent upon the automobile. Yet, while there are examples of large urban areas driving the implementation of infrastructure to support these modes within their jurisdiction, many communities with populations smaller than 10,000 people have yet to implement bicycle and pedestrian infrastructure. Perceived high costs, limited staff expertise, perception of contextual application (i.e., the viewpoint that the community is rural and therefore bicycle and pedestrian infrastructure does not fit) are some of the reasons why small communities report implementing limited if any bicycle and pedestrian facilities. Yet, there are some very small communities that are leading the way to implement bicycle and pedestrian infrastructure for their residents. This research project asks: what are the factors that have enabled communities of less than 10,000 people to successfully implement bicycle and pedestrian infrastructure?

The communities identified in Table 1 were included for this study. Those with an asterisk (*) after their name were categorized as exemplary communities, meaning that they were generally found to have more examples of bicycle and pedestrian infrastructure as compared with the other promising communities (i.e., those without the asterisk $\left({ }^{*}\right)$ ).

Table 1: Interviewed Communities

\begin{tabular}{|l|l|l|}
\hline Maine & Minnesota & New Hampshire \\
\hline Bath* & Breckenridge* & Bethlehem \\
\hline Damariscotta & Cold Spring & Bridgewater \\
\hline Gardiner* & Deer River & Bristol* \\
\hline Gouldsboro & Deerwood & Gorham* \\
\hline Machias & Dodge Center* & Henniker \\
\hline Ogunquit* & Frazee* & Hopkinton \\
\hline Vassalboro & Grand Marais* & Littleton* \\
\hline Vinalhaven & Hanover & Shelburne \\
\hline Yarmouth* & Little Falls* & Troy* \\
\hline & Olivia* & Walpole* \\
\hline & & Warner \\
\hline
\end{tabular}

The following maps show where these communities are located within the States of Maine (Figure 1), Minnesota (Figure 2), and New Hampshire (Figure 3). A close-up of the coastline of Maine is provided to show that Vinalhaven is an island (Figure 4). 


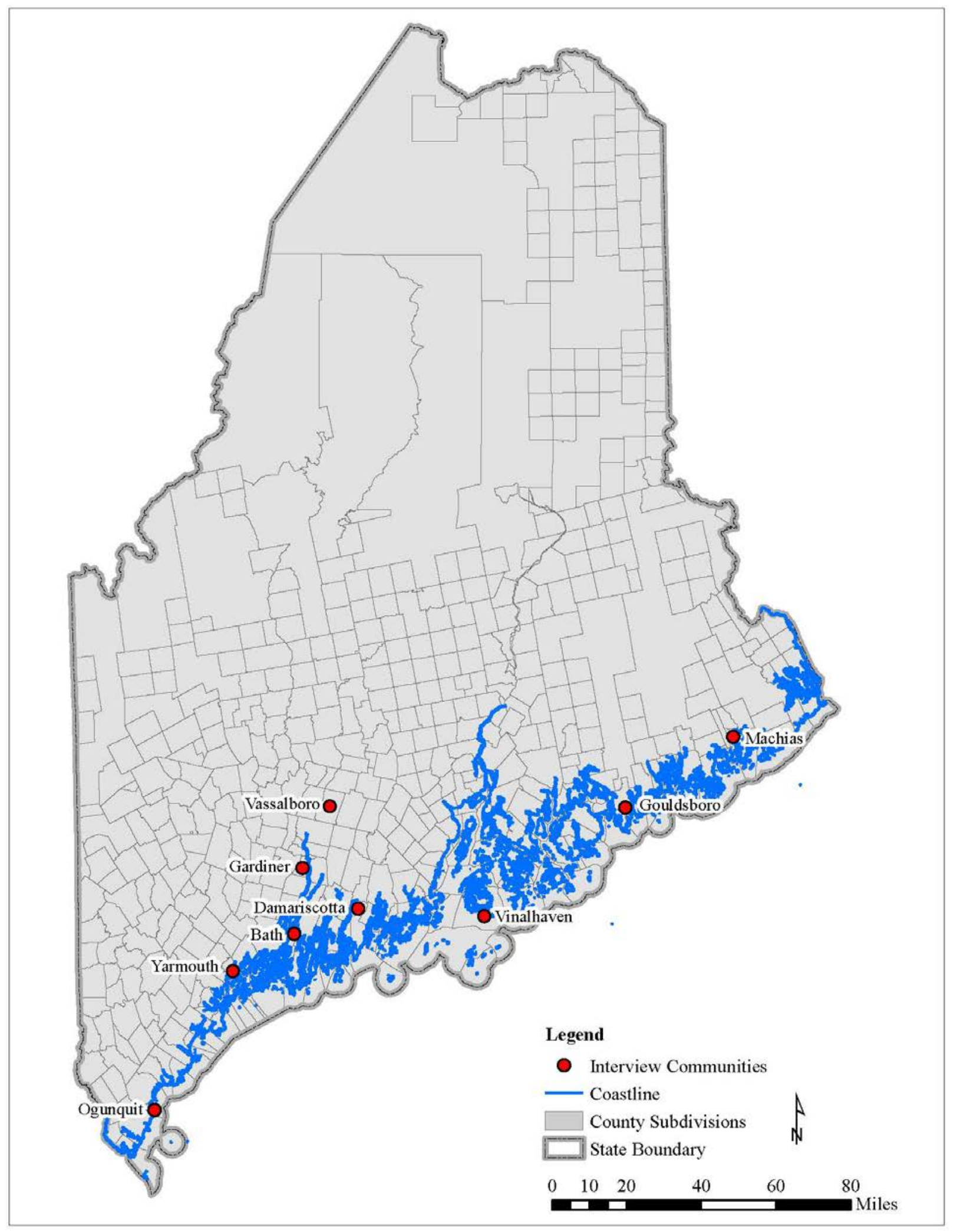

Figure 1: Communities within Maine 


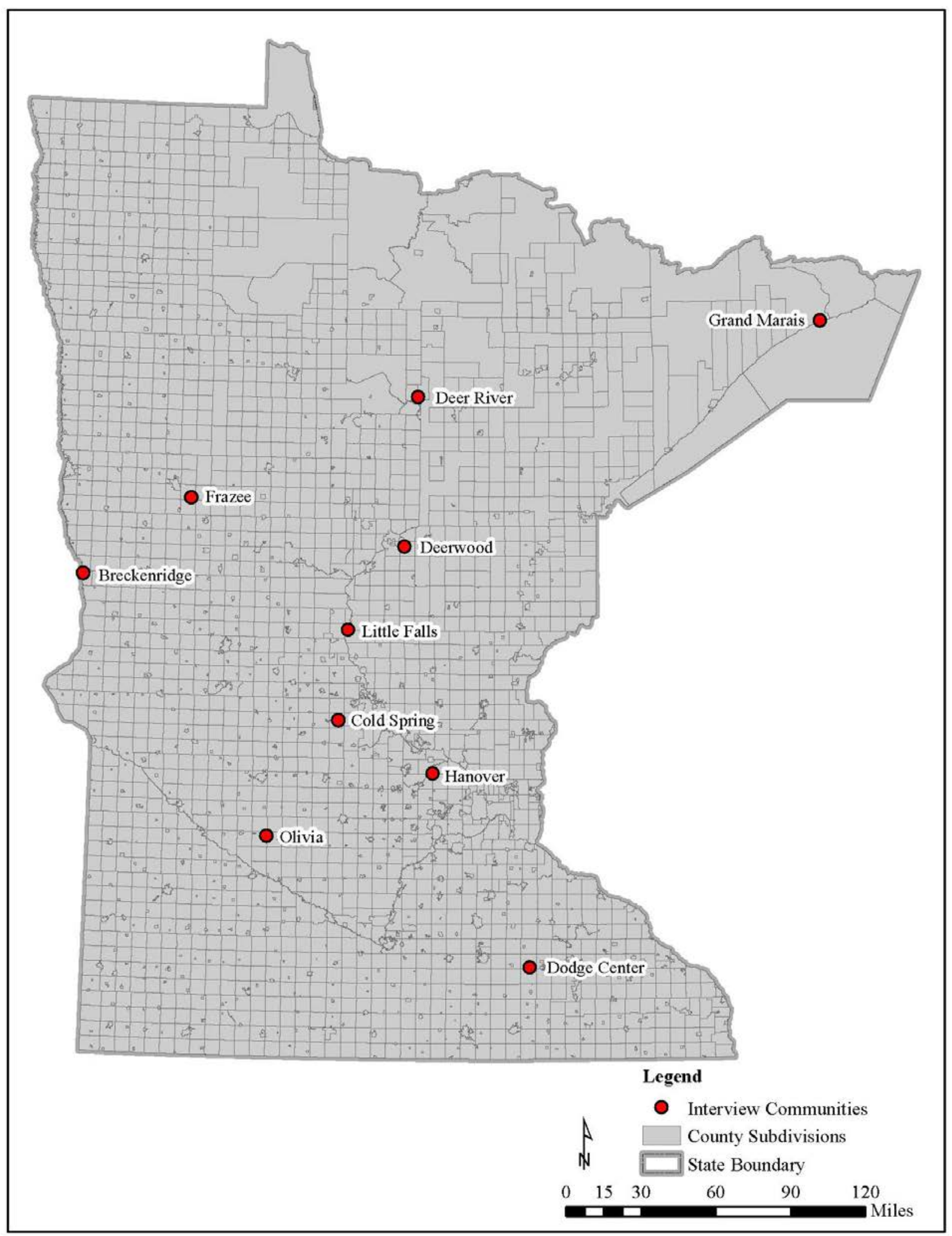

Figure 2: Communities within Minnesota 


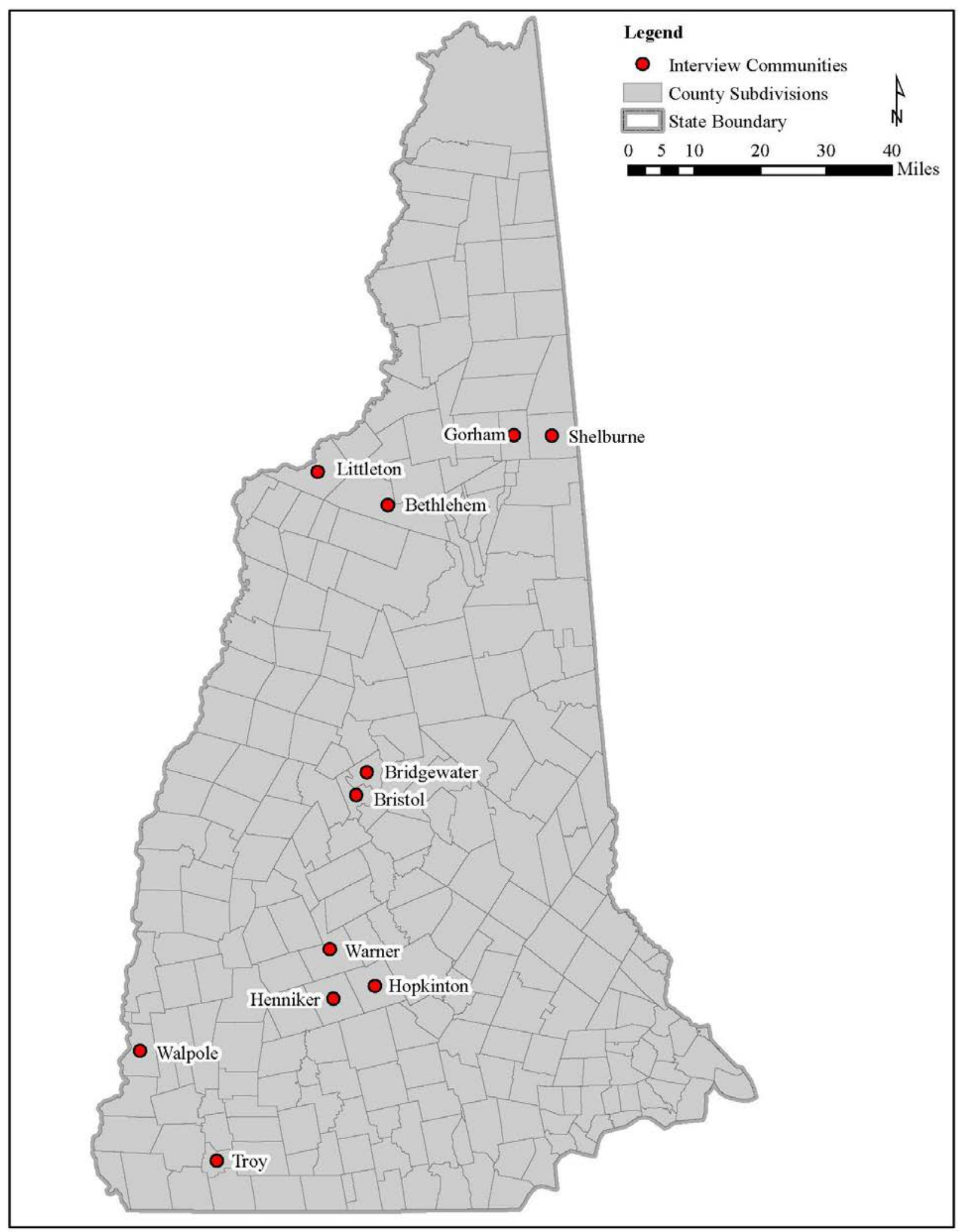

Figure 3: Communities within New Hampshire 


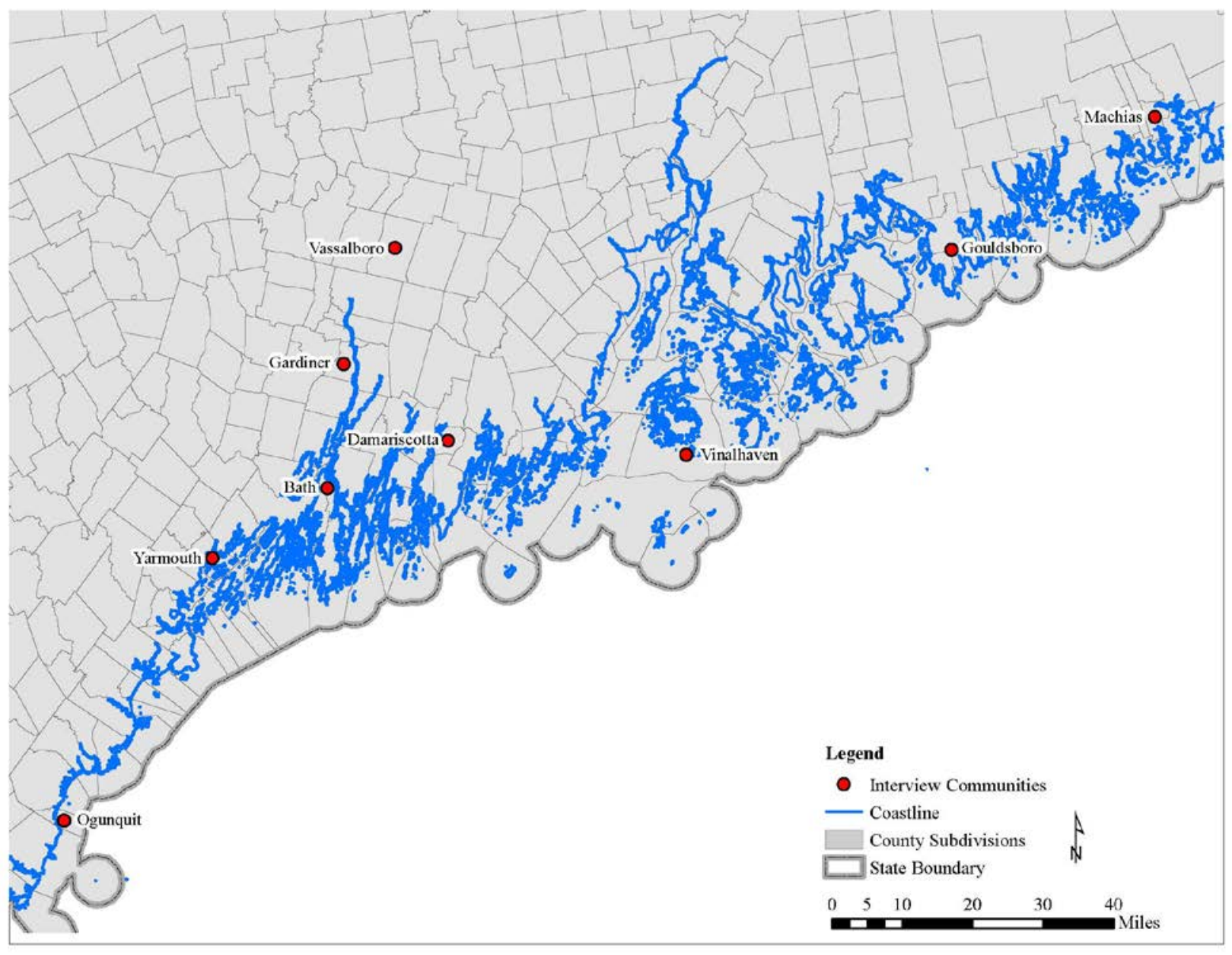

Figure 4: Close-Up of the Maine Coast

As Figure 1 shows, the Maine communities were primarily located in the southern part of the state. The stakeholders from the Maine Department of Transportation had indicated a preference for including these communities. While fairly well dispersed, the communities selected from Minnesota (Figure 2) do not include the northwest and to a lesser degree the southwest region of the state. In New Hampshire (Figure 3), the communities were clustered in several groups, with the intent of having both an exemplary and promising community in relative proximity. Overall, future research projects could expand not only within the states, but across the United States. While the researcher and stakeholders attempted to consider a broad geographic subset of communities from all three states, the primary objective was to collect three interviews (one from a planner/town administrator, one from an advocate, and one from an elected official) from four exemplary and four promising communities per state, for a goal of seventy-two interviews. Eighty-two interviews were collected in total, thereby exceeding the goal. Table 2 summarizes the number of interviews administered in each community in the three states. 
Table 2: Interviews Administered, by Community

\begin{tabular}{|c|c|c|c|c|c|}
\hline $\begin{array}{c}\text { Maine } \\
\text { Community }\end{array}$ & Interviews & $\begin{array}{l}\text { Minnesota } \\
\text { Community }\end{array}$ & Interviews & $\begin{array}{c}\text { New Hampshire } \\
\text { Community }\end{array}$ & Interviews \\
\hline Bath* & 3 & Breckenridge* & 4 & Bethlehem & 3 \\
\hline Damariscotta & 4 & Cold Spring & 1 & Bridgewater & 2 \\
\hline Gardiner* & 3 & Deer River & 3 & Bristol* & 4 \\
\hline Gouldsboro & 3 & Deerwood & 1 & Gorham* & 3 \\
\hline Machias & 4 & Dodge Center* & 1 & Henniker & 3 \\
\hline Ogunquit* & 2 & Frazee* $^{*}$ & 3 & Hopkinton & 3 \\
\hline Vassalboro & 4 & Grand Marais* & 3 & Littleton* & 3 \\
\hline Vinalhaven & 1 & Hanover & 3 & Shelburne & 1 \\
\hline \multirow[t]{3}{*}{ Yarmouth* } & 3 & Little Falls* & 3 & Troy* & 4 \\
\hline & & Olivia* & 3 & Walpole* & 1 \\
\hline & & & & Warner & 3 \\
\hline TOTAL & 27 & & 25 & & 30 \\
\hline
\end{tabular}

As Table 2 demonstrates, interviews from more than eight communities were collected, because interviews representing the desired three categories were not always attainable. More than 150 individuals were approached to obtain the eight-two complete interviews.

The objective of this study was to better define underlying factors that have allowed communities of less than 10,000 people within three states (Maine, Minnesota, and New Hampshire) to successfully implement bicycle and pedestrian infrastructure. These factors were defined by first conducting a thorough literature review along with general information gathering, as there is little published knowledge about communities of less than 10,000 people. Based on the information collected and synthesized, questions were developed to ask leadership and advocates within communities of less than 10,000 people that have successfully implemented bicycle and pedestrian infrastructure, and to ask those agencies that have shown potential to implement bicycle and pedestrian infrastructure. Finally, the information was synthesized within this report so that the lessons learned can be shared with other departments of transportation and communities of less than 10,000 people.

This report starts by presenting the methods through which the data was collected. The next section summarizes additional literature that has been collected and reviewed since the initial literature review table was created (Task 3). Subsequently, the Minnesota data from the Mobility Mindset of Millennials in Small Urban and Rural Areas (Villwock-Witte \& Clouser, 2016) which was tied to individuals living in communities of less than 10,000 people is summarized. Next, a synopsis of Task 4, which summarizes the information shared during the interviews is provided. The subsequent section provides a synopsis of Task 5, which compares the literature reviewed in 
Task 3 with the entire sample of interviews. The final sections present the conclusions based on the research effort and recommendations for future research. 


\section{METHODOLOGY}

The following discussion provides information on: 1) why the participant states were selected, 2) how communities within the states were selected, 3) how questions for elected officials and advocates were created, and 4) why interviews were selected as the data collection mechanism.

Three states ultimately participated in the study: Maine, Minnesota, and New Hampshire. States (Minnesota, Montana, Washington State, and Wisconsin) that participated in a previous study, the Mobility Mindset of Millennials in Small Urban and Rural Areas (Villwock-Witte \& Clouser, 2016), were approached for participation first, as there was an interest in using the data collected from that study for an initial analysis. For various reasons (e.g. staff availability, funding allocation timing, etc.), only Minnesota was able to participate. Select bicycle and pedestrian coordinators in the remaining forty-six states were then approached to determine if they would be interested in the study, typically based on the results of a preliminary literature search to identify available information about bicycle and pedestrian infrastructure in communities of less than 10,000 people. Ultimately, Maine and New Hampshire indicated an interest in understanding more regarding bicycle and pedestrian development in small communities, which was the final focus of the study.

Communities within the three participating states that had a population of 1 to 10,000 people were included as possible candidates for further analysis. Table 3 presents the number of communities in Maine, Minnesota and New Hampshire with less than 10,000 people, but also subdivided into 1-4,999 people and 5,000-9,999 people. It is interesting to note that all three states have a large number of very small communities (less than 5,000), greatly exceeding the number of communities between 5,000 and 10,000 people. 10,000 people was selected as the upper threshold in large part to focus on the smallest of communities in the U.S.

\section{Table 3: Number of Communities with Less Than 10,000 People in Maine, Minnesota \&} New Hampshire

\begin{tabular}{l|cc}
\multicolumn{1}{c}{ State } & $\begin{array}{c}\text { Number of } \\
\text { Communities } \\
\text { 1-4,999 }\end{array}$ & $\begin{array}{c}\text { Number of } \\
\text { Communities } \\
\mathbf{5 , 0 0 0 - 9 , 9 9 9}\end{array}$ \\
\hline Maine & 469 & 43 \\
\hline Minnesota & 710 & 46 \\
\hline New Hampshire & 191 & 40 \\
\hline
\end{tabular}

The communities were ultimately selected based on the recommendations from the researcher along with the level of interest by the state department of transportation. Therefore, while all communities ultimately interviewed had less than 10,000 people, the chosen communities were not necessarily a random selection. This was done in part because there was concern regarding the level of implementation of bicycle and pedestrian infrastructure in these smaller communities.

The questions for the study were developed as a result of findings from the literature review and insight provided by the state department of transportation stakeholders. The literature review table completed for Task 3 can be found in the Appendix. 
The researchers chose to use an interview approach as compared with an online survey or on-site review for a variety of reasons. First, it was unclear as to what extent of implementation these very small communities would have with respect to bicycle and pedestrian infrastructure. Second, an interview allows the researcher to collect a more flexible sample of information as compared with other methods, like online surveys that often use simple "yes or no" questions. The researcher can also ask an interviewee to elaborate on shared information that is particularly relevant to the research study at hand. Therefore, significantly richer information can be collected and considered, which can be used in future research efforts that focus on these very small communities. Ultimately, it is expected that knowledge collected from these smallest communities that have successfully implemented bicycle and pedestrian infrastructure can be shared with other similarly sized communities interested in implementing bicycle and pedestrian infrastructure within their community. 


\section{LITERATURE REVIEW \& INFORMATION GATHERING}

Task 3, Literature Review \& Information Gathering included as deliverables a Literature Review Summary Table and Review of the Existing Dataset. This section presents the former; the next section presents the later. As the project progressed, the author identified additional sources of literature that were relevant to the project at hand. These are presented below.

A study by Miranda-Moreno et al. (Miranda-Moreno, Morency, \& El-Geneidy, 2011), which used data from Montreal, Canada, sought to understand the link between the built environment and 1) pedestrian activity and 2) crashes involving pedestrians. Built environment includes land-use characteristics, demographics, transit supply, and road network characteristics. The authors concluded that the specific built environment characteristics of population density, commercial land use, number of jobs, number of schools, presence of a metro station, number of bus stops, percentage of major arterials and average street length are all highly correlated with pedestrian activity.

In the Safe Routes to School National Partnership's Safe Routes to School: How States are Adapting to a New Legislative Framework (Colvin, Pedroso, \& Mennesson, 2014), the authors interviewed 10 state department of transportation Safe Routes to School (SRTS) coordinators to better understand how changes from the SAFETEA-LU federal transportation bill to MAP-21 were impacting the implementation of SRTS projects. Maine was one of the states featured in their review. The authors noted that by not requiring a match "small, rural and low-income communities with limited tax bases and financial resources" were able to use SRTS funding. They cited seventy percent of SRTS funding during SAFETEA-LU was given to disadvantaged schools (i.e., includes those in rural areas). The twenty percent match requirement associated with the Transportation Alternatives Program (TAP), which ultimately replaced SRTS funding, was identified as a significant barrier to small, rural and low-income communities. Similarly, by combining the SRTS program into TAP, the authors noted that small, rural and low-income communities would likely be challenged to:

- Plan for SRTS projects,

- Fill out SRTS applications, and

- Go through the federal process associated with TAP.

The report provided statistics from 2012, showing that 22,000 children ranging in age from 5 to 15 were injured, and 270 were killed on their way to or from school. They identified one study that showed that in New York City, SRTS projects were found to contribute to a reduction in pedestrian injuries among school children. They also cited improvements in the rates of walking and bicycling by school children. With the reduction in funding for the SRTS program, in that it was often combined into TAP by many states, cases like Kansas, where \$11 million was available for $\$ 40$ million worth of project requests, were common. Maine saw one of the biggest cuts in funding (46.6\% reduction) of the 10 interviewed DOTs. Maine tried to address the challenge of small, rural and low-income communities in applying for projects by implementing a "revolving open-ended selection process" that would allow communities to pursue funding without having to reapply. Maine was also reported as adding funding to TAP and requiring an impact on a school as criteria for TAP projects, citing a benefit to projects impacting SRTS. Florida and Ohio indicated that they provided the twenty percent match for SRTS projects after the legislation change. Overall, the authors concluded that there was a significant reduction in SRTS projects. They recommended that states retain their SRTS programs. They suggested that 
it would ensure competitive projects and that the easier application process is more appealing to small, rural and low-income communities.

In an article entitled, “The Cities That Spend The Most On Bike Lanes Later Reap The Most Reward (Peters, 2014)," the author cites findings from a study out of Auckland, New Zealand, which suggests that minimum bicycle infrastructure will not contribute to much change in the use of the bicycle mode. Instead, if a more comprehensive, wide-reaching, better quality infrastructure is developed, the cities will find significant benefits when considering the 1) health of their community members, and 2) reductions in traffic and pollution. The author found that slowing traffic speeds along with creating a network of separated bicycle lanes could increase the use of the bicycle mode by $40 \%$, whereas only implementing a bicycle lane in a few locations can only be expected to increase bicycle use by $5 \%$. The article also suggested that the latter approach has been associated with more bicycle injuries and deaths (i.e., implementing bicycle lanes in only a few locations), and that fears associated with safety could take a long time to dispel. More interestingly, the author suggested that Auckland is similar to many U.S. cities and therefore the results are applicable to the U.S.

Table 4 summarizes The League of American Bicyclists (LAB) state ranking, the number of bicycle friendly communities in each state, the number of bicycle friendly businesses in each state and the number of bicycle friendly universities for each stakeholder state (The League of American Wheelmen, Inc., n.d.).

Table 4: LAB State Ranking, Number of Bicycle Friendly Communities within Stakeholder States, Number of Bicycle Friendly Businesses, Number of Bicycle Friendly Universities

$\begin{array}{lllll}\text { State } & \begin{array}{l}\text { Bicycle Friendly } \\ \text { State Ranking }\end{array} & \begin{array}{l}\text { Number of Bicycle } \\ \text { Friendly Communities }\end{array} & \begin{array}{l}\text { Number of } \\ \text { Bicycle Friendly } \\ \text { Businesses }\end{array} & \begin{array}{l}\text { Number of } \\ \text { Bicycle Friendly } \\ \text { Universities }\end{array}\end{array}$

\begin{tabular}{l|c|c|c|c|}
\hline Maine & 11 & 2 & 2 & 2 \\
\hline Minnesota & 2 & 23 & 69 & 5 \\
\hline New Hampshire & 34 & 5 & 1 & 2 \\
\hline
\end{tabular}

The Bicycle Friendly Businesses are in Freeport, Maine, a community which was not included in this analysis because it has a population greater than 10,000. Bath, Maine, is one of the two Bicycle Friendly Communities in Maine. Frazee and Grand Marais, Minnesota, were identified as Bicycle Friendly Communities in Minnesota. All Bicycle Friendly Communities in New Hampshire had more than 10,000 people in them. 


\section{SUMMARY OF EXISTING DATASET FINDINGS}

As part of the literature review, this project reviewed data from communities of less than 10,000 people in Minnesota, which had been collected for a preceding project, Mobility Mindset of Millennials in Small Urban and Rural Areas (Villwock-Witte \& Clouser, 2016). (Note: Data was also collected from Montana, Washington State, and Wisconsin.) The write-up can be found in, Analysis of Minnesota Communities with Less Than 10,000 People (Villwock-Witte, 2018). Communities were identified by the zip codes provided by the survey respondents. An important finding from the study is that rural participants were reached more often by telephone when compared with urban participants, which helped inform the approach of calling interviewees for the project at hand. The researcher anticipated that using this personal approach would result in collecting more information. Almost ten percent of the 181 survey respondents who were from Minnesota communities of less than 10,000 people reported being unemployed. While the majority of the survey respondents (88\%) indicated that they drove on a weekly basis, $44 \%$ indicated that they walked and 9.4\% indicated that they biked in an average week. (Note: The question asked, "In a typical week, which of the following forms of transportation do you use? (Check all that apply.) Automobile, walk, and bicycle were three of the thirteen options presented.) It is important to note that four times the number of respondents indicated that they walked as compared with bicycling. When survey respondents were asked their preference for travel, little interest beyond the personal automobile was reported. This implies that some respondents who currently report walking would prefer to drive. Future research efforts could seek to identify if this is a reflection of culture, where walking and biking are perceived as being only done by lowincome or those with driving infractions (e.g. driving under the influence), or if there is an impact related to the quality of bicycle and pedestrian infrastructure or gaps in connectivity of bicycle and pedestrian infrastructure. When asked whether sufficient transportation options were available, survey respondents from communities of less than 10,000 in Minnesota largely disagreed that they had many transportation options available, with $42 \%$ indicating either disagree or strongly disagree and only $24.9 \%$ indicating agreement. This result is not surprising in that the Minnesota Department of Transportation is aware of the limited public transportation systems available to rural users and the limited infrastructure to support walking and especially bicycling. Cost was reported as a significant factor in how a survey respondent traveled, with the majority of survey respondents agreeing that it was significant, and the agreement category having the largest representation.

The majority (63.5\%) of Minnesota survey respondents from which data was collected for the Mobility Mindset of Millennials in Small Urban and Rural Areas study indicated that their community was not walkable. However, it is notable that a Battle Lake survey respondent had strongly agreed that the community is walkable, based on findings that will be discussed in subsequent sections. (Note: Battle Lake representatives were contacted for this research project, but no reply was received.) Similarly, Frazee, which was included in this research project as an exemplary community, was identified by a survey respondent in the Millennial study as being walkable, with an agree affirmation by a survey respondent. Other communities that were identified as walkable by respondents, who selected either "Strongly agree” or "Agree" were: Balaton, Becker, Brook Park, Brownton, Canby, Chisholm, Clarkfield, Cleveland, Cottonwood, Dawson, Frazee, Glencoe, Grey Eagle, Jackson, Kensington, Long Prairie, Lanesboro, Longville, Luverne, Maynard, McIntosh, Montevideo, Montrose, Mora, New London, Pennock, Perham, Pine City, Pipestone, Richville, Sandstone, Silver Bay, Swift, Truman, Two Harbors, Tyler, 
Wadena, Webster, and Wells. Future work could take knowledge learned from this research project to inform outreach efforts or additional data collection efforts focusing on these communities. A future quantitative research project could expand on the data collected in this study by querying the aforementioned communities and others identified in other states, requesting them to answer either an online or telephone survey.

When survey respondents were asked how strongly they agreed with the statement, "Being able to bike for everyday travel influenced where I chose to live,” only eight survey respondents from Battle Lake, Brook Park, Cottonwood, Kensington, Longville, McIntosh, Royalton, and Swift reported "Strongly Agree" with the statement. (Note: The researcher had approached Royalton representatives for the study at hand but was redirected to another community; Royalton declined to participate.) Again, future research could include these communities as candidate communities for which more information could be gathered or efforts to implement bicycle and pedestrian infrastructure could be focused.

Survey respondents were asked how strongly they agreed with the statement, "I chose where I live based on the proximity of leisure bicycling options." Survey respondents from Battle Lake, Cottonwood, Longville, Royalton, Truman, and Swift all chose "Strongly Agree” when presented with this statement.

Survey respondents were asked how strongly they agreed with the statement, "The presence of bicycle lanes, multi-use paths, and/or bike share make bicycle transportation possible where I live." Respondents choosing "Strongly Agree” were from the following communities: Altura, Battle Lake, Chisholm, Cottonwood, Dakota, Glencoe, Granite Falls, Kensington, Littlefork, Montrose, Truman, Tyler, and Swift. It is interesting to note that some who indicated that they strongly agreed that the presence of bicycling lanes, multi-use paths, and/or bike share make bicycling where they live possible, did not also indicate that their community was conducive to everyday bicycling or that their community had good recreational bicycling opportunities.

When survey respondents were asked, "Would you like to see more bike lanes, multi-use paths, and/or bike share where you live?” responses were slightly skewed towards "no.” Many suggested that the one multi-use facility or the like was sufficient; this suggestion does not seem to be informed by the research conclusions made by Macmillan et al. (Macmillan, et al., 2014), which suggest that only having limited bicycle lanes can result in a dangerous, very infrequently utilized facility. There seems to be a bit of a disconnect in the understanding of residents regarding the relationship between the presence of connected infrastructure and use. Outreach efforts that provide information to individuals to help explain why a more developed network is safer and will be utilized by more people is likely needed, with a potential comparison to the automobile network. Many respondents who indicated "no" also commented that bicycle facilities did not match with the rural nature of their community.

Survey respondents were also asked, "Would you like to see more sidewalks where you live?" Surprisingly, considering that $44 \%$ of respondents had indicated that they walked in an average week, the majority, and more so than for bicycling, indicated that they did not see the need for more sidewalks. Of those who did, connectivity seemed to be a big issue. One respondent expressed concern over the difficulty of using the sidewalk network with a stroller. Another noted the difficulty in connecting with a multi-use pathway. However, similar to responses related to bicycling, some survey respondents suggested that sidewalks were not appropriate as a result of the rural nature of their community. Survey respondents who suggest that sidewalks, bike lanes 
and other infrastructure that can be implemented to support bicycling and walking are not consistent with the rural context seem to do so in spite of a growing body of research that would refute this assertion. For example, the Small Town and Rural Multimodal Networks guide (Alta Planning + Design, Small Urban and Rural Livability Center - Western Transportation Institute, National Association of Counties, 2016) provides insight and examples of bicycle and pedestrian infrastructure that may be more common or contextually appropriate for rural areas.

Overall, the results of the analysis suggest that Battle Lake, Cottonwood, and Swift, Minnesota (correlated with zip codes 56515, 56229, and 56763) should be included in future research studies regarding bicycle and pedestrian infrastructure in communities of less than 10,000 people in Minnesota, as they were identified by respondents in four questions as having promising walking or bicycling environments (Villwock-Witte, Analysis of Minnesota Communities with Less Than 10,000 People, 2018). 


\section{INTERVIEW FINDINGS}

Task 4, Local Agency Interviews (Villwock-Witte, Local Agency Interviews, 2018), for this project, Bicycle \& Pedestrian Infrastructure Improvements Realized in Communities of Less Than 10,000 People, summarizes the conclusions based on a subset of the final sample, fifty-seven interviews in twenty-six communities of less than 10,000 people in Maine, Minnesota and New Hampshire that were categorized as both promising and exemplary. Interviewees were asked a series of questions that provided the researcher with information on the community regarding:

1) Its growth (increasing, staying the same, or decreasing),

2) If there was an institution of higher education in the community,

3) Whether or not it was a tourist destination,

4) If it had a historic/preservation district,

5) The posted speed limits within the community,

6) Whether or not the community had champions for bicycle and pedestrian infrastructure/travel,

7) If bicycle and pedestrian modes were used for transportation,

8) How the interviewee would describe the community land use,

9) Whether or not events with road closures would occur,

10) If there were programs that taught bicycling,

11) Whether or not neighborhood groups were present,

12) If there were bicycle/pedestrian groups,

13) The respondent's familiarity with bicycle/pedestrian infrastructure,

14) An understanding of the community project approval process,

15) The types of bicycle/pedestrian infrastructure that can be found within the community if any,

16) Funding used to date to create bicycle and pedestrian infrastructure,

17) Barriers to implementing bicycle and pedestrian infrastructure,

18) Ways that the community could see the department of transportation helping regarding implementing bicycle and pedestrian infrastructure, and

19) Recommendations that the community might have for other small communities if they had success in implementing bicycle and pedestrian infrastructure.

The first thirteen topics are discussed below regarding whether or not these characteristics were found in exemplary and promising communities. Then after, summaries of findings regarding bicycle and pedestrian infrastructure implemented, funding used, barriers identified, ideas for how DOTs could support the communities, and recommendations for other communities are provided.

\subsection{Characteristics That Impact Implementation}

The following did not seem to impact whether or not a community of less than 10,000 people had implemented bicycle and pedestrian infrastructure: whether or not a community was growing, the presence of an institution of higher education, whether or not a community is a tourist destination, the presence of a preservation district, whether or not bicycles and walking are seen as a transportation mode, community land use, events with road closures, neighborhood groups, and an interviewee's familiarity with bicycle and pedestrian infrastructure. 
When asked whether or not a community was growing, there was little consistency within a community regarding an interviewee's viewpoint; therefore, it was concluded that it did not have an impact or that an alternative measure may be needed. When asked whether or not an institution of higher education was present in the community, many interviewees referenced a "nearby" institution. These "nearby" institutions were often in a neighboring community, typically relatively close but potentially from a rural viewpoint of "close." More often than not, the nearby community often had a larger population. As examples from each state, Breckenridge, MN referenced the institution across the river in Wahpeton, ND; Gorham, NH referenced an institution in Berlin, NH; and Gouldsboro, ME referenced an institution in Ellsworth, ME. When asked if a community was a tourist destination, it did not appear that this was a defining factor as to whether or not a community had bicycle/pedestrian infrastructure. However, one interesting finding is that if a small community was considered a "hub" for other small communities, there is a possibility of influence. By and large, all communities seemed to report bicycling and walking as a recreational interest, often describing it as being for commuting only by the "hardy" and/or lowincome citizens. While there was a suggestion by interviewees that some barriers, like a national forest or large areas dedicated to parks, may limit sprawl of a small community as potentially influencing whether or not pedestrian and/or bicycle facilities were present, in general, there do not seem to be substantial differences between exemplary and promising communities regarding land use. Future research could ask more directed questions and compare the either positive or negative response (i.e., yes or no) across communities to make more definitive conclusions.

Interviewees often proudly described events held within their communities, although few noted that roads were closed off to host the event, often noting that state roads prohibited any road closures as they may delay through traffic. Many interviewees expressed confusion when asked about neighborhood groups; it seems that a small community may be similar in size to a neighborhood group of a large metropolitan area. Few interviewees suggested that they knew little regarding bicycle and pedestrian infrastructure, yet many suggested that by just seeing such infrastructure in larger cities, they were knowledgeable in the area. For future research efforts, asking a respondent about specific types of infrastructure or to pair infrastructure types with names and comparing the results, using some more difficult or atypical infrastructure types would likely provide a better understanding regarding how well an interviewee understood various types of infrastructure. It should be noted that in many cases, interviewees suggested that they did some research prior to the interview (e.g., looked up Census Bureau numbers).

The following did seem to impact whether or not a community of less than 10,000 people had implemented bicycle and pedestrian infrastructure: perception of motorist obedience to speed limits, having champions for bicycle and pedestrian modes, offering programs that supported bicycling and walking within a community, the presence of a bicycle/pedestrian group within a community, and the community project approval process.

Generally, of the communities considered in the three states, respondents from Minnesota reported higher posted speed limits than Maine and New Hampshire. However, rather than the posted speeds, the perception of speed reported by interviewees seemed to relate to whether or not bicycle and pedestrian infrastructure was present. In the communities where more bicycle and pedestrian infrastructure was identified, speeding problems were often not described as being as notable as those without such infrastructure.

While bicycle and pedestrian champions were sometimes identified in promising communities, they were often few and far between. In many cases, in promising communities, it was often just 
one person. If there was some reason why the champion was no longer able to fill this role (e.g. moving, change of jobs), interviewees often reported no movement regarding implementing bicycle and pedestrian infrastructure. In contrast, exemplary communities often identified numerous champions, which seemed to provide additional enthusiasm and to sustain any changes if one or more of the champions were no longer able to dedicate time to the efforts.

While interviewees were often more specifically asked about programs that taught a person how to bicycle, some respondents also mention groups of community members who would gather to walk. The majority of exemplary communities reported some type of program that taught a person how to bicycle, although these programs were often directed at children. The programs were often offered through the police department, recreation center, and/or school.

Multiple national, state, regional and local bicycle groups were often described by interviewees from exemplary communities. Many also noted active bicycle and/or pedestrian groups within the community.

With regard to the project approval process, communities in Maine and New Hampshire generally reported that the once-a-year budget meetings seemed to be problematic for implementing bicycle and pedestrian infrastructure. The primary reason is that with many federal funding opportunities, a twenty percent match is required. Therefore, the project would have to be timed with the meeting where budgets for an entire year are approved. In addition, those communities that described their approval processes as relatively easy also seemed to be more successful in implementing bicycle and pedestrian infrastructure. Respondents from these communities also seemed to put less emphasis on tying the projects to taxes.

The historic nature of a community resulted in two different conclusions based on how much data was collected. With fifty-seven interviews across twenty-six communities conducted, having historic qualities seemed to influence whether or not a community had bicycle/pedestrian infrastructure. However, with the complete sample (i.e., eighty-two interviews across thirty communities), it was concluded that this was not the case (see Section 6). Since varying sample sizes seem to result in contradicting conclusions, it would be ideal to obtain more data regarding this quality, especially from additional states, to better understand whether or not a community having historic character does in fact influence whether or not a community has bicycle and pedestrian infrastructure. For this effort, interviewees were simply asked, "Does your community have a historic district or preservation district?” The National Register of Historic Places can designate a 1) district, 2) site, 3) building(s), and 4) objectives that are significant in American history, architecture, archeology, engineering and culture (National Park Service, U.S. Department of Interior, n.d.). For future efforts, a more definitive definition is recommended. It was suggested that since many historic communities were built at pedestrian scale, they may be particularly influential regarding whether or not pedestrian facilities exist. Furthermore, because lower speed limits were reported as being associated with grandfathering exceptions, lower speeds were identified and are often thought to provide comfort to both pedestrian and bicycle modes. Future research could include additional states with a mix of historic and non-historic communities of less than 10,000 people, some with implemented pedestrian and bicycle infrastructure and some with little to no infrastructure implemented, thereby creating a more balanced sample. 


\subsection{Infrastructure Implemented, Funding, Barriers, Wish List, \& Recommendations}

Promising communities either did not identify any bicycle and pedestrian infrastructure or identified the more common types of bicycle and pedestrian infrastructure: sidewalks and trails/multi-use pathways. In contrast, exemplary communities reported having rectangular rapid flash beacons (RRFBs), bump-outs, speed feedback signs, having tried a parklet, sharrows, advisory bike lanes, and bike racks. These communities also reported conducting a sidewalk inventory and doing demonstration projects.

The funding identified related to the extent of implemented bicycle and pedestrian infrastructure - the more infrastructure implemented, the more funding sources identified. Communities which were more successful in implementing bicycle and pedestrian infrastructure also identified a variety of funding sources beyond federal funding. Some communities also noted that the recession hit them hard, as some projects that were programmed for implementation were delayed. Finally, many communities, whether exemplary or promising, noted that a shrinking tax base was problematic.

There were several similarities between barriers identified in exemplary and promising communities: weather (e.g., long, cold winters), the need to prioritize basic infrastructure (e.g., sewers, fixing potholes), limited space, and maintenance (e.g., clearing of snow from sidewalks in the winter).

When asked about the type of assistance desired from the state department of transportation, funding was one of the most frequently stated requests from all communities, regardless of whether or not they were categorized as exemplary or promising. Many respondents also indicated that the twenty percent match was challenging (required as part of the Transportation Alternatives Program (TAP)), as identified by Colvin et al. (2014).

Communities also asked for the opportunity to work collaboratively with their state DOT when state projects impact the community. Communities were appreciative of their state department of transportation for providing an extension of staff by overseeing projects that are implemented in the community, assisting the community with applying for funding, allowing technical experts to contribute to designs (e.g. designing curb ramps to American with Disabilities Act (ADA) standards), and providing the communities with support in how to maintain existing sidewalks.

Some communities identified creative ideas for potential types of support from the department of transportation. One suggestion was providing an intern that could work with the community for part of the summer in planning for bicycle and pedestrian infrastructure. Another idea was to hold a workshop within the community, providing lunch or snacks, where information about bicycle and pedestrian infrastructure would be shared. Another interviewee also suggested providing information, ideally in hard copy handouts, of successful examples of bicycle and pedestrian infrastructure in peer communities.

Communities that have had success in implementing bicycle and pedestrian infrastructure provided some good suggestions for peer communities: good communication, reframing viewpoints to focus on commonalities, obtaining input from businesses in peer communities, being proactive, and implementing incremental improvements. (Note: More details can be found in the Task 5 report (Villwock-Witte, Synthesis of Findings, 2018).) One of the recommendations given by many was good communication with the public and fellow staff. For example, interviewees suggested talking 
about the bicycle and pedestrian infrastructure frequently with the public, to get community members accustomed to hearing about the ideas. Furthermore, interviewees suggested communicating with maintenance personnel to consider maintenance of any proposed facilities; they suggested that there may be some comparable designs that require less maintenance. They recommended reframing what may seem like conflicting viewpoints of community members, suggesting instead that there are often more commonalities than differences if the point of dissent is considered in-depth. They suggested talking with businesses in peer communities that have successfully implemented bicycle and pedestrian infrastructure to learn how it benefits the community financially. A future research project could investigate the impacts of bicycle and pedestrian infrastructure on businesses in communities of less than 10,000 people. They suggest being proactive, not waiting for a bicyclist or pedestrian to die to spur action (the death of a child was cited in two of the communities, where in one community interviewees specifically identified the fatality as spurring the implementation of a multi-use pathway). Finally, they suggest thinking about incremental improvements as compared to large, mega-project changes. These smaller, incremental projects are often lower in cost, more manageable, and will enable the community to see results in a more expedited fashion. 


\section{INTERVIEWS COMPARED WITH LITERATURE FINDINGS}

Task 5, Synthesis of Findings (Villwock-Witte, Synthesis of Findings, 2018), for the project Bicycle \& Pedestrian Infrastructure Improvements Realized in Communities of Less Than 10,000 People, compares the findings of all eighty-two interviews across thirty communities of less than 10,000 people in Maine, Minnesota and New Hampshire to that found in the literature. The following are some key findings when comparing the literature to the information shared during the interviews. The discussion also highlights some key findings that may not be directly tied to the literature reviewed for the study.

Research using data from large American cities suggested that a community with larger proportions of students also has greater levels of bicycling to work (Buehler \& Pucher, 2012). While the current research project did not collect data on the number of people bicycling, we can consider if there is an impact as a result of an institution of higher education being present within a community. When considering communities of less than 10,000 people, only five of the thirty communities had institutions of higher education. The limited number of institutions of higher education is not surprising in that in Geography and College Attainment: A Place-Based Approach (Ruiz \& Perna, 2017), the authors suggest that there are limited post-secondary opportunities in smaller communities. There were many references by interviewees to institutions in a neighboring community. Because of the limited number of post-secondary institutions, and with many being present in promising but not exemplary communities, it can be concluded that there does not seem to be an influence on the proportion of bicyclists in the community.

Langdon (2017) suggested that the historic nature of Battleboro, Vermont was influential in making the community walkable. However, based on the final data collected in this study where 28 communities identified as historic and 34 did not (exemplary communities being even more skewed in this direction with 16 versus 20 as compared with 12 versus 14 for promising communities), it would seem that viewing one's community as historic does not necessarily influence whether or not a community is walkable. Yet, there is likely more that needs to be investigated when considering this topic. For example, what does a historic classification entail (e.g., does it have to be an official designation; does a community have to have one or several designated historic buildings, does a community have to promote its historic attributes for tourism to qualify)? A definition was not clearly identified for the project, rather, interviewees were asked whether or not their community was historic. Further research should better define what makes a community historic or create quantitative metrics (e.g., the number of official historically designated buildings), so that it can be more definitively compared with the bicycle and pedestrian infrastructure found within a community.

Speed was identified as playing a part both in the literature and from the feedback of interviewees. One source suggested that the speed of a facility was in fact part of the infrastructure (Andersen, 2017). More recently, the National Transportation Safety Board (NTSB) produced a report specifically citing the critical relationship between speed of impact and the likelihood of a pedestrian fatality (National Transportation Safety Board (NTSB), 2017). Research has also shown that the likelihood of a pedestrian fatality during a crash with a motor vehicle is significantly greater, the greater the speed of the motor vehicle prior to the crash; for example, a $20 \mathrm{mph}$ crash has a significantly lower likelihood of the pedestrian dying as compared with a crash between a pedestrian and a motor vehicle when the motor vehicle is traveling at $40 \mathrm{mph}$ (Schmitt, 2016). Many interviewees noted that their downtown core often has lower speed limits. However, many 
also noted that they would prefer lower speed limits in the downtown core area, suggesting that congestion and multiple uses may warrant these reductions. However, they also indicated that they expect that the state would not allow speed reductions if a speed study was done in the corridor. They noted that the department of transportation often utilizes an $85^{\text {th }}$ percentile recommendation, which one literature source noted as being derived from a study on rural highways (ColvilleAndersen, 2018), not taken from data from within a downtown core, even though the $85^{\text {th }}$ percentile is often applied in urban areas and downtown core areas. A future research effort could study recommendations regarding speed limits in downtown areas of small communities.

Langdon suggested that “one person can make a difference” regarding bicycle and pedestrian infrastructure (Langdon, 2017). By contrast, from the communities interviewed for this study, communities that were most successful seemed to have an army of people working to implement bicycle and pedestrian infrastructure. In promising communities, with few people pushing for bicycle and pedestrian infrastructure, if these supporters moved or had something change in their life that would cause them not to have time to champion the cause, the push to implement bicycle and pedestrian infrastructure seemed to fizzle out.

Xing et al. (2010) reported that bicycling-inclined people were often attracted to bicycling-friendly communities, although it is unclear how much bicycle infrastructure a community must have before it is able to attract bicycling-inclined people. Comments by at least two interviewees seemed to suggest that this had occurred in two separate small communities within the study (Bath, $\mathrm{ME}$ and Littleton, $\mathrm{NH}$ ). One interviewee noted living in a nearby larger community that struggled to gain political support to implement bicycle and pedestrian infrastructure. As a result, this individual indicated that he had relocated to the smaller community which had been successful in implementing the bicycle and pedestrian infrastructure. Another interviewee noted that he had moved from a larger out-of-state community to the smaller community; implications were that he had previously visited the smaller community on vacation. Future research could explore if these phenomena, which was reported in the literature and by interviewees, also holds for the walkability of a community.

Bike paths and bike lanes were reported as being associated with greater bike commuter rates for large American cities (Buehler \& Pucher, 2012). While many interviewees in exemplary communities noted that there was some bicycle commuting occurring, interviewees did not paint a much different picture than promising communities in that most interviewees suggested that bicycling was primarily done for recreation. Yet, at least one interviewee suggested that while bicycle and pedestrian facilities may initially be viewed as recreational, he suggested that over time, the community may see how these facilities can be used for transportation purposes. Overall, there was only one reference to some type of count done to understand use. Performing counts, or asking specifically for counts, could be part of a future research effort.

Several studies noted an impact of topography on one's interest in using bicycle and pedestrian facilities (Cervero, Sarmiento, Jacoby, Fernando Gomez, \& Neiman, 2009) (Hemken, et al., 2011). Interviewees also noted the impact of topography on expected use, particularly interviewees from New Hampshire, who often noted the hilly nature of their communities as impacting bicycling and walking, although there was often more of an emphasis on the former. Interviewees from Grand Marais, Minnesota, noted that since the community extends up from the shores of Lake Superior, this topography does potentially impact some use. Yet, this community was also awarded Bicycle Friendly Community status by LAB, which implies that topography influences can be overcome (The League of American Wheelmen, Inc., n.d.). 
Research has suggested that if walking and/or bicycling within a community is considered "normal," it will be done more often, particularly for bicycling (Buehler \& Pucher, 2012). Data from Minnesota for the study, Mobility Mindset of Millennials in Small Urban and Rural Areas (Villwock-Witte \& Clouser, 2016), showed that walking seemed to be preferred, and was often considered as being more "normal" than bicycling because it was reported five times more often than bicycling in a typical week. The "normalization" of a mode is related to how commonly the mode is used. Walking also seemed more accepted across generations, and the data from interviewees suggests a similar finding. In fact, at least one interviewee suggested that in his/her community, those who are working tend to drive whereas individuals who are retired tend to walk. More interviewees seemed to consider walking to be normal, and when asked more specifically about bicycling, there was often hesitation. Further, bicycling was often seen as being for children or those with low income, sentiments that were also seen in the literature (Hemken, et al., 2011). Some interviewees reported some scary situations for bicyclists who were "buzzed" or harassed by motorists. At least one community noted that a multi-use pathway was created in response to the death of a teenager that was hit when walking alongside the roadway; a second community noted that a child had been hit and killed by a vehicle, although it was not clear if an interest in implementing bicycle/pedestrian infrastructure was the consequence. Future research should investigate the cultural phenomena associated with those in a motor vehicle feeling as though they can harass a person that has no physical protection around them when walking or bicycling. It seems as if there is a disconnect between the severity of a driver's actions and the possibility of hitting a bicyclist or pedestrian.

The ability to access everyday services in a downtown was described as making a community more walkable, and in some cases more bikeable (Miranda-Moreno, Morency, \& El-Geneidy, 2011). It essentially relates to keeping the core at a pedestrian scale (Hemken, et al., 2011). Communities often referenced the challenges of zoning, some noting that no zoning regulations had been approved in the past because of the more rural nature of part of the community. Others noted that zoning can encourage multiple uses, which many exemplary communities noted as everyday needs being found in downtown cores, whereas many promising communities suggested that such services could be found in a neighboring community.

At least one community noted that the Bicycle Coalition of Maine (BCM) having an event that stopped in the community spurred an interest in developing bicycle and pedestrian facilities (e.g., multi-use trails). The interviewee perceived a positive impact from the bicycle riders camping out for the night in the community and hosting a large, community-wide dinner. Future research could investigate the impact of state-level bicycling groups hosting events in smaller communities and the impact that such events do or do not have in the community considering bicycling and/or walking infrastructure in the future.

While the cause and effect cannot be determined through this research effort, it is clear that exemplary communities are more likely to offer programs that teach bicycling. Furthermore, these communities move beyond just offering such programs for children, with courses for adults and in some cases, courses tailored to women. Courses were most often offered through a police department, although recreation centers (in communities that had them), community events, schools, and local bike shops/foundations were all identified as entities that offered a program(s). It appears that there might be some relationship between a community having 2,500 people or more and the presence of a recreation center or department. Future research could investigate if this is another subdivision within these smaller communities where potentially state bicycle 
advocacy groups or other non-profits could provide opportunities for smaller communities (i.e., less than 2,500 people) to offer programs.

When asked about whether or not neighborhood groups exist within their community, many interviewees responded with confusion because neighborhood groups do not exist in such small communities. Therefore, neighborhood groups were not found to have any influence regarding whether or not bicycle and pedestrian infrastructure in a community of less than 10,000 was implemented.

All statewide bicycle advocacy groups (e.g., Bicycle Coalition of Maine (BCM), Bike-Walk Alliance of $\mathrm{NH}$, Bicycle Alliance of Minnesota (BikeMN)) were identified by at least one interviewee. And, in many cases, the influence of these organizations was cited several times within an interview and by multiple interviewees. Therefore, these results suggest a finding that was not sought after through this research, but which is very informative - the statewide bicycle advocacy groups are known by individuals in communities of less than 10,000 in Maine, Minnesota and New Hampshire.

Interviewees were asked about their familiarity with bicycle and pedestrian infrastructure. Overall, all interviewees suggested that they were well-versed on the topic. However, some suggested that their knowledge was based on traveling to a larger city and seeing some of the infrastructure (e.g., Concord, NH or Minneapolis, MN). A few interviewees cited previous positions they held in bicycle advocacy groups or referenced the recently released, Small Town and Rural Multimodal Networks guide (Alta Planning + Design, Small Urban and Rural Livability Center - Western Transportation Institute, National Association of Counties, 2016). Future research efforts should ask about one's familiarity with specific types of infrastructure, ranging from common (e.g., sidewalks, bike lanes) to less common (e.g., bicycle advisory lanes, RRFBs, and HAWKS) bicycle and pedestrian infrastructure, allowing an interviewee or survey respondent to choose their level of familiarity with a scale from strongly agree to strongly disagree to obtain a quantitative level of familiarity that can be more easily compared. As noted earlier, this research effort was interested in better defining underlying factors that have allowed communities of less than 10,000 people within three states (Maine, Minnesota, and New Hampshire) to successfully implement bicycle and pedestrian infrastructure.

When asked about the community approval process and the expected acceptance of leadership within the community, interviewees discussed the following topics: not wanting change, assuming minimal bicycle infrastructure is all that is needed, limited number of community meetings annually (e.g. typically one), grant funding matches, and concerns about maintenance. The lack of connectivity and influences of the type of infrastructure on the type of users were hinted at research has shown that a limited number of "Interested but Concerned" users will use bicycle facilities if there is only a painted line on a roadway (KTU+A Planning and Landscape Architecture, Ryan Snyder Associates, U.S. Department of Housing and Urban Development, 2014). The annual meetings of small towns in Maine and New Hampshire were identified as problematic when a $20 \%$ funding match is required for programs like the Transportation Alternatives Program (TAP), as a lot of pre-planning has to be done to coordinate the dates of the project with the annual town meeting to secure approval of such funding. In contrast, it was noted that the Safe Routes to School program did not require any match (Colvin, Pedroso, \& Mennesson, 2014). One interviewee even questioned, "is the New England town meeting...an effective form of government?" An interviewee noted that if a special meeting was held to consider funding matches, such meetings are not well-received by community members and the funding request 
would likely be denied. It was also observed that promising community interviewees cited maintenance of bicycle and pedestrian infrastructure more often than exemplary communities. Therefore, providing examples of how communities smaller than 10,000 have overcome these maintenance barriers could potentially help peer communities with implementing bicycle and pedestrian infrastructure. As an example, one interviewee suggested that Battle Creek, Minnesota, which reportedly installed a sidewalk corridor that has been successfully maintained throughout winter, would be one such good example to share with other communities. A future research project could investigate how small communities have overcome maintenance barriers.

Overall, many communities identified some innovative implemented bicycle and pedestrian infrastructure (e.g. bicycle advisory lanes, rentable adaptive bicycles (discussed in (VillwockWitte \& Leidekker, 2015)), wayfinding with maps, police bicycles (discussed in (Villwock-Witte, Gleason, \& Shapiro, 2011)), bumpouts, bike maintenance stations, electric bike charging stations, bike lending program) in addition to more typical bicycle and pedestrian infrastructure (e.g. bike lanes, sidewalks). They also identified innovative practices (e.g. sidewalk audits used to prioritize replacement (Li, et al., 2018), demonstration projects (suggested by (Langdon, 2017)), and bicycle friendly businesses). However, at least one interviewee noted that a demonstration of a new type of infrastructure may not have gone as well as hoped. Several interviewees noted that while some bicycle infrastructure exists in their community (e.g. a bike lane and sharrows), the facility may not be the best design (i.e., "People don't like to ride those [bike lanes] because they're between the car doors and the driving lane.").

While sidewalks seemed to be on the radar of most interviewees, providing crossings, particularly those that would bring more awareness or safety to bicyclists and pedestrians, seemed to be overlooked. In fact, several respondents asked what a HAWK was, which suggests that they are unaware of this treatment. This would not be entirely surprising for Maine, where as of June 2018, no HAWKS were installed in the state; however, many interviewees, including those from Maine, identified as being knowledgeable about available bicycle and pedestrian infrastructure (Adams, 2018). When asked about infrastructure, the communities in some cases identified needs. For example, Deer River MN noted that while it has mapped where sidewalks are, it does not have information on the condition of the mapped sidewalks. Many communities referenced the value of planning, and in many cases, having a complete streets document developed for the community. Many comments suggested that there was a lack of understanding regarding how types of bicycle and pedestrian infrastructure may influence user types ( (KTU+A Planning and Landscape Architecture, Ryan Snyder Associates, U.S. Department of Housing and Urban Development, 2014), (Garrard, Rose, \& Lo, 2008), (Macmillan, et al., 2014), \& (Buehler \& Pucher, 2014)). One interviewee stated, "our ideal is infrastructure with separation from the travel lane..." Another interviewee noted, "With one foot in metro and one in rural, he finds it weird to come to a city where they think grandma should walk in the street to go down and visit the neighbor." Several respondents suggested that due to low traffic levels on community streets or the inherent rural nature of the community, infrastructure for bicycles and pedestrians is not needed. Yet one interviewee reported observing children bicycling on sidewalks because of the lack of bicycle infrastructure. The viewpoint that infrastructure for bicycling and walking is not needed may be tied back to the early days of the automobile where the speeds that could be attained by them were relatively low. In contrast, speeds that can be achieved in a short duration are substantial and as mentioned earlier during the discussion about speed, automobiles traveling at high speeds are very dangerous for pedestrians and bicyclists. Future research could interview residents of small communities to understand if there are similarities between small communities and large cities like 
Portland, Oregon, to determine if residents would make use of facilities if they were provided (e.g. interested but concerned bicyclist-type).

It seemed at one point in time, sidewalks were viewed as a nuisance by many small communities in Minnesota and prompted some of these communities, including Battle Lake (according to an interviewee), to take all of them out. Yet, this same interviewee noted that Battle Lake decided that this was not the best solution and has since installed new sidewalks but made sure that the new installations could be maintained in the winter. The town prioritized a route where sidewalks were provided.

No community specifically referenced a counting program. A future research project could count walking and bicycling in some of these small communities to determine how weather (often noted as a challenge by many interviewees) and provided facilities may or may not impact use. For example, as questioned by some interviewees, does a roadway without sidewalks still see use by pedestrians? Do these pedestrians feel that they have a safe space to walk?

Many funding sources were identified by exemplary and promising communities alike, with a more varied list for the former. However, several communities noted the challenge of finding the twenty percent match as the price tag for projects increased, which was also identified in the literature (Colvin, Pedroso, \& Mennesson, 2014). Several additional funding sources that were not specifically identified by interviewees were found during searches by the author, including PeopleforBikes Community Grant Program, Rails-to-Trails Conservancy's webpage on Financing and Funding (which had some of the identified funding sources but also others), and the Doppelt Family Trail Development Fund. In addition, as noted by at least one interviewee, funding sources may also be identified by word of mouth. For example, talking to a regional planner, state department of transportation representative, or a state advocacy organization can assist a community with identifying other potential funding sources. This can be done by an email or call to a representative found by searching a relevant website. As funding sources change over time, approaching these same contacts annually to identify any new potential sources is recommended.

Many barriers were identified: available land, competing funding demands, perceptions of use, maintenance, limited volunteers, and challenges of managing federal projects. Interviewees suggested that feelings about land ownership were unique to the northeast. Yet, the literature suggests that the fight over ownership of land is not unique to the east (Riccardi, 2017). As expected, funding was cited by many as a barrier. However, some provided informative context. For example, one interviewee explained that while town residents are very supportive of bicycle and pedestrian infrastructure, the town would have to choose between replacing an outdated fire truck or matching the funding for a bicycle and pedestrian infrastructure project. Many communities specifically called out limitations on their taxing authorities, like not being able to add on a lodging tax or municipal revenue sharing not being returned to the communities from the state. Overall, there were several instances of resistance to providing infrastructure for these modes. One of the most extreme viewpoints was the interest by a representative in creating legislation to force bicyclists to pay for insurance, register and pay for the inspection of their bicycles annually. This was reportedly in response to the representative's viewpoint that bicyclists were not paying their fair share for roadways, even though few communities reported bicyclespecific infrastructure, and if there was such infrastructure it was limited in scale and there were some concerns with design. At least one interviewee suggested that in ten years, the viewpoints may change. An individual in a leadership position at a school insisted that since he did not see any kids walking on a specific street, there were no users. Yet, once a project was implemented 
to provide a sidewalk on this road, the individual observed it being used and this experience changed his mind. Maintenance was identified as a barrier. Many cited competing needs for time, whether it is from staff at the administration level of the community or by volunteers in a community. The researcher saw this in the process of approaching individuals to serve as an interviewee, when an exasperated administrator indicated simply that she had no time to talk. Several interviewees identified the challenge of having a project funded by federal dollars where aspects of the design and paperwork can complicate the intent of the project and thereby dissuade small communities from pursuing such funding.

Overall, feedback from the communities regarding state assistance has been positive. However, it seems that there may be a disconnect between bridge engineers within a state department of transportation and a state department of transportation's effort to accommodate bicycle and pedestrian modes on bridges. Feedback suggests there is a need to better educate bridge engineers within state departments of transportation on the need to design bridges to accommodate bicycling and pedestrian modes, particularly as these facilities are commonly designed for at least a 50-year design life. Along these lines, many communities suggested that DOTs see bicycle and pedestrian provisions as upgrades to the design, rather than a standard part of the design. With complete streets policies referenced for at least two of the states, this approach does not seem to support the complete streets policy. A request commonly heard for the state DOTs from communities was to assist them with facilitating the connections between small communities by providing bicycle/pedestrian facilities on (or parallel to) the state roads that currently travel between them. Some interviewees suggested that this would not just be wider shoulders, but rather pathways for bicyclists and pedestrians separated from the roadway. Some communities asked if the DOTs could provide workshops with hard copies of handouts, not just email PDFs or links to documents.

Having awareness of a peer community that has had success was suggested as a way that a state department of transportation could provide assistance; discussing successful communities could be part of the workshop. It could also facilitate connections between the communities if they are in relative proximity, which was an interest expressed by many small community interviewees. Interviewees also asked for handouts on successful projects. A future research project could involve documenting, with photos and additional detailed information, projects that have successfully been implemented in small communities. Several interviewees asked for assistance from the DOT to help create more well-defined crossings on state roads that run through the downtown core. Several interviewees suggested a connection between economic impact and the implementation of bicycle and pedestrian facilities. A future research project could assess the impact of investments in bicycle and pedestrian facilities on economic development, using towns that have demonstrated success as case studies.

Several interviewees suggested that while there were many DOT representatives who were supportive of bicycle and pedestrian infrastructure, there were also many who did not view such infrastructure as vital, and a few of these individuals were identified as going as far as to try to curtail efforts by the community to implement bicycle and pedestrian infrastructure. Some interviewees suggested that while they have an interest in bicycle and pedestrian infrastructure for their community, they are stuck when considering what questions to ask. Many expressed that they value the expertise available at the DOT level and would be interested in identifying opportunities to make use of that expertise. This could include engineering design, assistance with grant writing, an example of how to obtain easements, or the creation of maps. 


\section{CONCLUSIONS}

This research sought to better understand how communities of less than 10,000 people in Maine, Minnesota, and New Hampshire have been able to successfully implement bicycle and pedestrian infrastructure. While in many cases the bicycle and pedestrian infrastructure that is implemented may not be extensive, the researcher was encouraged by the approaches used, and by the efforts of individuals who implemented bicycle and pedestrian infrastructure in these communities. The following factors seem to influence whether or not a community of less than 10,000 people is able to successfully implement bicycle and pedestrian infrastructure:

- The speed limits, particularly adherence to speed limits within a community,

- Having many champions for bicycle and pedestrian modes,

- Having programs to teach or support bicycle and/or pedestrian modes,

- Having bicycle and/or pedestrian groups, and

- The community approval process.

To elaborate on these characteristics, it was not just the speed that was posted but also whether or not the community required that road users adhered to them that were found to impact whether or not a community reported successfully implementing bicycle and pedestrian infrastructure. One champion of bicycle and pedestrian travel was not found to be enough but rather a group that would support these modes. Programs that taught bicycling to children and adults, particularly women and older adults were identified in exemplary communities. A group within the administration structure, most commonly a bicycle and pedestrian group was also typical of exemplary communities. Communities that were successful with implementing pedestrian and bicycle modes often reported that their local government had an easy approval process for projects that would support these modes.

The following characteristics were found not to influence whether or not bicycle and pedestrian infrastructure can be found within a community of less than 10,000 people:

- Population growth or decline,

- Presence of an institution of higher education,

- Identification as a tourist destination,

- Identification as a historic or preservation district,

- Description of bicycle and pedestrian modes as transportation,

- Land use within the community,

- Events hosted with road closures,

- Presence of neighborhood groups, and

- Familiarity by leadership and advocates with bicycle and pedestrian infrastructure.

This study ultimately concluded that the historic nature of a community did not influence whether or not a community has been successful in implementing bicycle and pedestrian modes. However, it should be noted that further analysis of this issue would benefit from a more descriptive definition of what entails a historic community, as well as a data sample that can provide a broader cross-section of such communities. 
Future Research

\section{FUTURE RESEARCH}

This research project provided a better understanding of the status of communities of less than 10,000 people in Maine, Minnesota and New Hampshire in implementing bicycle and pedestrian infrastructure. Clearly, the experience of these communities is different than the larger metropolitan areas and even of communities just over 10,000 people. Many communities expressed an interest in additional support from the departments of transportation. Examples of suggestions include: 1) hosting workshops on the topic of bicycle and pedestrian infrastructure, 2) providing an intern for some period during a summer to help move their efforts forward, 3) to collect data to understand what the magnitude of use of existing bicycle and pedestrian infrastructure (e.g., counts), or 4) to gather additional information regarding public perception and understanding of these types of facilities. A future research project could involve developing case studies for bicycle and pedestrian infrastructure in communities of less than 10,000 people to show other small communities that such infrastructure can be applied. Additional, systematic information along with more thorough photos and potentially some before and after data would be gathered for the case studies.

The questions developed for this research project were intentionally general, to try to get a broader perspective of adoption of this type of infrastructure within these small communities. Future research efforts can build on this knowledge with more directed, yes or no, types of questions. This would allow for a more quantitative analysis. One example would be to provide images or the names of specific bicycle and pedestrian infrastructure, and then ask either with a yes or no type question if respondents have heard of this type of infrastructure.

Analysis using two different cuts of the data provided different conclusions regarding the impact of the historic nature of a community as a predictor of whether or not the community was walkable and/or bikeable. Future research efforts could choose communities for inclusion based on a specific definition of what a historic community represents; in addition, these efforts could ensure that a random sample of communities within and without this definition were used for the analysis to draw more definitive conclusions regarding its impact. It would be of value to obtain more information regarding zoning and its impacts on the historic aspects of community.

The culture of Americans was discussed by several interviewees and their level of acceptance of walking and bicycling as modes of transportation. Future research efforts should investigate how a person in a motor vehicle does or does not understand the vulnerability of those walking and bicycling. Many interviewees suggested that a few people, whether volunteers or representatives, often hindered programs that supported bicycling and walking. State departments of transportation and/or bicycle and/or pedestrian advocacy groups should investigate ideas on how additional resources and support can be provided to communities of less than 10,000 people.

Finally, "strong and fearless" and "interested and concerned" were categories given to bicyclists in Portland, Oregon. Do such categories apply to residents in communities of less than 10,000 people? A future research project could investigate whether or not a similar paradigm applies to these small communities. 


\section{APPENDIX}

\section{LITERATURE REVIEW SUMMARY TABLE}




\begin{tabular}{|c|c|c|c|}
\hline \# & Title & Description & $\begin{array}{c}\text { Bike/ } \\
\text { Ped }\end{array}$ \\
\hline 1 & $\begin{array}{l}\text { Creating Walkable \& } \\
\text { Bikeable Communities } \\
\text { https://www.huduser.gov } \\
\text { portal/sites/default/files/ } \\
\text { pdf/Creating-Walkable- } \\
\text { Bikeable- } \\
\text { Communities.pdf }\end{array}$ & $\begin{array}{l}\text { One of the strengths of this document was its ability to summarize much of the guidance } \\
\text { and standards related to pedestrian and bicycle travel. However, it is a very long } \\
\text { document; and therefore, it might be difficult to reach its intended audience, "community } \\
\text { leaders, elected officials, and interested persons," who may have limited time to review } \\
\text { it. An interesting aspect about this document is it indicated that the intent was to "focus } \\
\text { on small to mid-size communities with low to moderate income." The U.S. Department } \\
\text { of Housing and Urban Development (HUD) developed this document because the agency } \\
\text { identified that many Community Development Block Grants (CDBG) were being used } \\
\text { for infrastructure. }\end{array}$ & 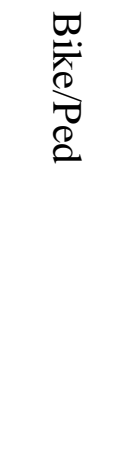 \\
\hline 2 & $\begin{array}{l}\text { Influences of Built } \\
\text { Environments on } \\
\text { Walking and Cycling: } \\
\text { Lessons from Bogotá } \\
\underline{\text { http://www.tandfonline.c }} \\
\underline{\text { om/doi/full/10.1080/155 }} \\
\underline{68310802178314}\end{array}$ & $\begin{array}{l}\text { The researchers investigated how infrastructure and the built environment influenced } \\
\text { walking and bicycling behavior. The researchers asked, "Do such relationships between } \\
\text { the built environment and time spent walking and cycling also hold for cities in the } \\
\text { developing world, such as Bogota?" Could a similar question be asked for the study at } \\
\text { hand, "Do such relationships between the built environment and time spent walking and } \\
\text { cycling also hold for communities of less than 10,000?" They grouped the neighborhoods } \\
\text { by four variables: socio-economic status, average slope of terrain, proximity to bus rapid } \\
\text { transit stations, and a variable related to public parks. } 1500 \text { people were asked to complete } \\
\text { a survey. Walking for utilitarian purposes was found to be predicted significantly by } \\
\text { street density and the connectivity index. Another factor found to positively influence } \\
\text { walking for utilitarian purposes was the age of the respondent, specifically those in the } \\
\text { middle stages of their life. In contrast, other factors found to negatively influence walking } \\
\text { for utilitarian purposes were steeper topography, cars in the household, and those in } \\
\text { higher socioeconomic classes. The researchers did not find that built environment } \\
\text { variables influenced bicycling; however, they attributed it to limited cycling } \\
\text { infrastructure. They did find that the presence of a bicycle in a household had a } \\
\text { significant influence on someone bicycling for utilitarian purposes. }\end{array}$ & 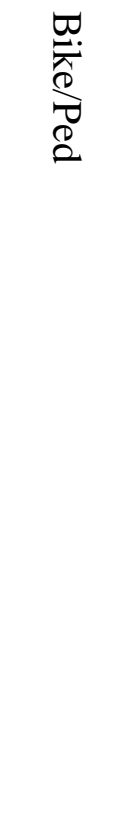 \\
\hline
\end{tabular}


3 Small Town and Rural Multimodal Networks

https://www.fhwa.dot.go v/environment/bicycle_p edestrian/publications/sm all_towns/fhwahep17024 lg.pdf https://ruralsafetycenter.o rg/resources/list/smalltown-and-ruralmultimodal-networkswebinar/

Complete Streets Policy: City of New Hope https://www.hennepin.us/ $=$

/media/hennepinus/yourgovernment/projectsinitiatives/completestreets/new-hopecomplete-streetspolicy.pdf?la=en
A report and webinar are both available. This guidebook provides resources, ideas, and guidance for communities that wish to support bicycle, pedestrian and other forms of active travel. The authors of this guidebook identified three types of facilities: 1) mixed traffic, 2) visually separated, and 3) physically separated. They also identified four contexts: 1) unimproved, 2) agricultural, 3) recreational, and 4) downtown. Hanover, New Hampshire (11,416 people) and Edina, Minnesota (49,300 people) were used as examples. Other communities with populations of less than 10,000 were also used as examples (Manzanita, Oregon: 3,000 people; Townsend, Montana: 7,700 people; Capay, California: 300 people; Montpelier, Vermont: 7,700 people; Lyndonville, Vermont: 1,200 people; Detroit, Oregon: 200 people; Denmark, South Carolina: 3,400 people; Jackson Hole, Wyoming: 9,600 people; Decorah, Iowa: 8,127 people; and Moab, Utah: 5,046 people). Design treatments/topics discussed include: 1) yield roadway, 2) bicycle boulevard, 3) advisory shoulder, 4) paved shoulder, 5) bike lane, 6) pedestrian lane, 7) sidepath, 8) shared use path, 9) sidewalk, 10) separated bike lane, 11) bridges, and 12) access to public lands.

This document nicely summarizes the importance of infrastructure. For example, the authors discuss the need for infrastructure planning. They also identify the need to "make infrastructure...changes to promote and support active living." An interesting tie that the document makes is that returning to a pedestrian-orientated environment is essentially more reflective of how historically pedestrian environments were created. However, they also indicate that creating a pedestrian-orientated environment is a nod to the future. The document cites six benefits that are achieved when designing complete streets: 1 ) safety, 2) providing options, 3) health, 4) community and economic development, 5) cost effectiveness, and 6) environment. An important point that they make when discussing these benefits is that forty percent of all Minnesotans cannot drive either as a result of age (too young or old), cannot afford a vehicle, are disabled, or choose not to. The fourth point is particularly important when considering the project at hand because many small communities, which are the focus of this study, are concerned with remaining economically competitive. The document also highlights another challenge of biking and pedestrians: the social normalization or lack thereof for these modes. There is currently a stigma associated with these modes in many parts of the United States where people who bike or walk are perceived to be poor. They also talk about the need for an 


\begin{tabular}{|c|c|c|c|}
\hline & & $\begin{array}{l}\text { interconnected transportation system; the implications are for all modes. The document } \\
\text { highlights another nuance of transportation systems, in that there may be many different } \\
\text { agencies in charge of a complex network of streets (e.g., city, county, state, federal). The } \\
\text { authors also highlight the challenges with adopting a complete street network as a result } \\
\text { of the existing infrastructure and land use framework. The authors acknowledge that the } \\
\text { creation of complete streets may be limited by topographic, environmental, historic or } \\
\text { natural resource constraints. In addition, the authors highlight the opportunity that aging } \\
\text { infrastructure presents: why not consider complete streets when repairing this } \\
\text { infrastructure? A relevant discussion in the current context, where government agencies } \\
\text { are grappling with the costs of maintaining many miles of road, is the benefit that smaller } \\
\text { roadway footprints can bring in terms of maintenance and repair. The end of the } \\
\text { document also has a map showing where all of the sidewalks in New Hope currently exist } \\
\text { and where they do not. Another map also shows the existing and proposed bikeway plan. }\end{array}$ & \\
\hline 5 & $\begin{array}{l}\text { Within Walking } \\
\text { Distance: Creating } \\
\text { Livable Communities for } \\
\text { All } \\
\text { https://islandpress.org/bo } \\
\underline{\text { ok/within-walking- }} \\
\underline{\text { distance }}\end{array}$ & $\begin{array}{l}\text { This book discussed six communities (City Center Philadelphia; The East Rock } \\
\text { Neighborhood, New Haven, Connecticut; Brattleboro, Vermont; Chicago's "Little } \\
\text { Village"; The Pearl District, Portland, Oregon; and The Cotton District, Starkville, } \\
\text { Mississippi) that have had success with creating walkable environments. While most of } \\
\text { these examples are within or next to large urban areas, it is worth considering if their } \\
\text { lessons learned may be of value to smaller communities. As Battleboro, Vermont and } \\
\text { Starkville, Mississippi were reported as having 12,000 and 23,000 residents, respectively } \\
\text { (i.e. smaller communities), additional findings from these locations follow, along with } \\
\text { relevant information from The Little Village and The Pearl District. Also, an overarching } \\
\text { summary of recommendations by the author is included. } \\
\text { In Battleboro, Vermont, 'The Current' is a Connecticut River Transit bus that connects } \\
\text { people outside of town to downtown Battleboro. Battleboro was also noted as having } 90 \\
\text { percent of its residents within two miles of the "well-preserved" downtown. The } \\
\text { community also passed an ordinance that restricted the development of new parking lots } \\
\text { to preserve the streetscape. Battleboro also has easy connectivity to local recreation trails } \\
\text { that can be reached by just walking out of town; no vehicle necessary. The author notes } \\
\text { that three pedestrian fatalities resulted in the recommendations for midblock crossings } \\
\text { and flashing lights. The average household income in Battleboro was reported at } \$ 41,000 \text {. }\end{array}$ & D \\
\hline
\end{tabular}




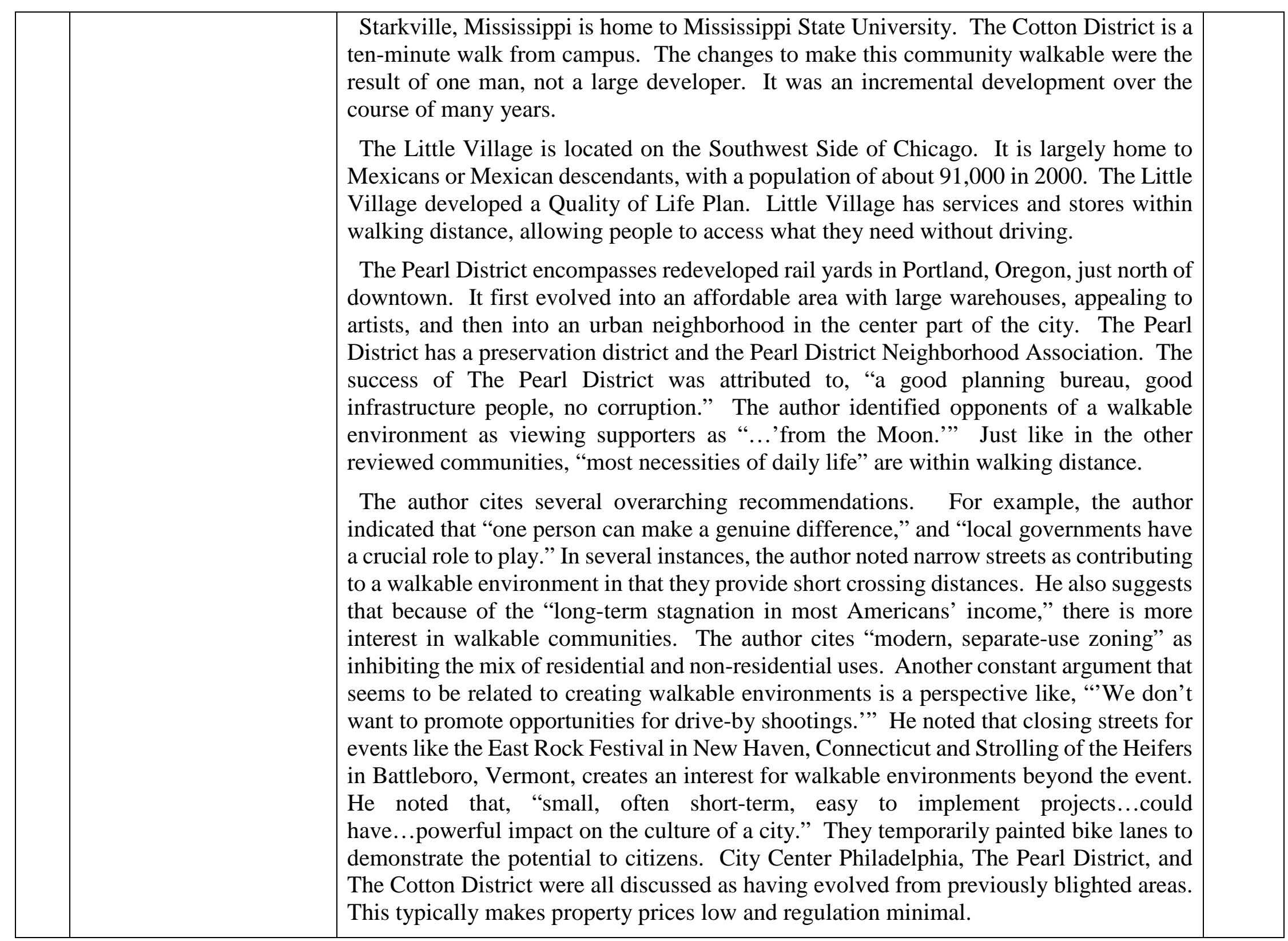




\begin{tabular}{|c|c|c|c|}
\hline & & $\begin{array}{l}\text { One significant point made by the author is that, "demand for walkable communities is } \\
\text { likely to be extremely strong through } 2030 \text { and probably beyond." }\end{array}$ & \\
\hline 6 & $\begin{array}{l}\text { Finding } \begin{array}{r}\text { Strategies to } \\
\text { Improve } \\
\text { Pedestrian }\end{array} \\
\text { https://ntl.bts.gov/lib/110 } \\
\underline{00 / 11500 / 11542 / \mathrm{UCNR} .} \\
\text { pdf }\end{array}$ & $\begin{array}{l}\text { This is an older report (2000) but relevant to rural US communities. The objective of this } \\
\text { effort was to study the safety of pedestrians crossing in rural areas to identify factors that } \\
\text { explain the higher rates of motor vehicle-pedestrian collisions at marked crossings. } \\
\text { Factors considered include population density, type of crossing, traffic control at crossing, } \\
\text { surrounding land use, highway facility type (road type), vehicle speeds, and vehicle and } \\
\text { pedestrian volumes. This is a two-part report, Part 1. Pedestrian safety in Maine, Part } 2 \text {. } \\
\text { Factors Influencing Injury Severity of Motor Vehicle-Crossing Pedestrian Crashes in } \\
\text { Rural Connecticut. } \\
\text { Part } 1 \text {. Pedestrian Safety in Maine Results } \\
\text { The safest crossing locations identified by this study are non-signalized, unmarked, low- } \\
\text { speed crossings. The marked but non-signalized crosswalks provide what feel like safe } \\
\text { locations for pedestrians to cross, but the vehicles do not necessarily see these crossings } \\
\text { or yield to them as they would if there was a signal. } \\
\text { The report finds that high speeds and wide roads lead to more crashes and recommends } \\
\text { that improvements be focused on arterials and major collectors. Suggested solutions to } \\
\text { improve safety include round-a-bouts, barriers to encourage pedestrians to use designated } \\
\text { cross walks, marking crossings with flashing lights or warning signs activated by } \\
\text { pedestrians, signs, installation of refuge islands (or if not feasible then barrels or cones), } \\
\text { narrowing the road, and reducing travel speeds. } \\
\text { Recommendations to improve pedestrian safety at crossings include evaluation and } \\
\text { implementation of education, enforcement, encouragement, and engineering (4E's). } \\
\text { Part } 2 \text {. Factors Influencing Injury Severity of Motor Vehicle-Crossing Pedestrian Crashes } \\
\text { in Rural Connecticut Results }\end{array}$ & D \\
\hline
\end{tabular}




\begin{tabular}{|c|c|c|c|}
\hline & & $\begin{array}{l}\text { Crash data analyzed considered pedestrians attempting to cross two-lane highways with } \\
\text { no signals in Connecticut. Variables that were found to significantly influence pedestrian } \\
\text { injury severity were: clear roadway width (full distance to cross - lanes and shoulders), } \\
\text { vehicle type, driver and pedestrian alcohol involvement, and pedestrians age } 65 \text { or greater. } \\
\text { Results showed that village, downtown fringe, and low-density residential areas } \\
\text { experienced higher pedestrian injury severity. } \\
\text { Based on these findings, the authors recommend speed-reducing measures be considered } \\
\text { for villages and downtown fringe areas, such as by narrowing the road width. }\end{array}$ & \\
\hline 7 & $\begin{array}{l}\text { The link between the built } \\
\text { environment, pedestrian } \\
\text { activity and pedestrian- } \\
\text { vehicle collision } \\
\text { occurrence at signalized } \\
\text { intersections } \\
\text { https://www.ncbi.nlm.nih } \\
\text { gov/pubmed/21658488 }\end{array}$ & $\begin{array}{l}\text { The authors sought to understand the relationship between the built environment (BE), } \\
\text { pedestrian activity, and accident occurrence. Data was collected from } 519 \text { signalized } \\
\text { intersections in Montreal, Canada. The authors define the built environment by 1) land } \\
\text { use characteristics, 2) demographics, 3) transit supply, and 4) road network } \\
\text { characteristics. The authors concluded that BE characteristics (population density, } \\
\text { commercial land use, number of jobs, number of schools, presence of metro station, } \\
\text { number of bus stops, percentage of major arterials and average street length) are all } \\
\text { strongly correlated with pedestrian activity. }\end{array}$ & $\begin{array}{l}7 \\
8\end{array}$ \\
\hline 8 & $\begin{array}{l}\text { Introducing the } \\
\text { Pedestrian Accessibility } \\
\text { Tool (PAT): Open Source } \\
\text { GIS-based Walkability } \\
\text { Analysis } \\
\text { http://blogs.ethz.ch/enga } \\
\text { gingmobility/files/2016/0 } \\
\text { 8/Erath-and-Van- } \\
\text { Eggermond-2016- } \\
\text { Introducing-the- } \\
\text { Pedestrian-Accessibility- } \\
\text { Tool-PAT.pdf }\end{array}$ & $\begin{array}{l}\text { The Singapore Urban Redevelopment Authority (URA) developed an open-source GIS } \\
\text { based tool called the Pedestrian Accessibility Tool (PAT). PAT aims to determine how } \\
\text { various factors (sidewalk width, traffic lights, etc.) influence a person's travel behavior } \\
\text { and perceived walking distance. Singapore URA used pedestrian network data along with } \\
\text { a survey of pedestrians' route preferences in order to create PAT. The URA tested PAT } \\
\text { through three case studies: (1) to determine perceived vs. actual walking distance, (2) } \\
\text { evaluate the benefit of replacing an overhead bridge, and (3) evaluate the accessibility } \\
\text { impact of adding a pedestrian crossing. It was determined that while the PAT is useful to } \\
\text { determine how infrastructure improvements could improve the accessibility of an area, } \\
\text { this tool is not useful for determining where to locate these improvements. }\end{array}$ & Dृ \\
\hline
\end{tabular}


$9 \quad$ Promoting transportation cycling for women: The role of bicycle infrastructure

https://www.ncbi.nlm.nih .gov/pubmed/17698185

Build It. But Where? The Use of Geographic Information Systems in Identifying Locations for New Infrastructure

Cycling http://www.tandfonline.c om/doi/abs/10.1080/1556 8318.2011.631098

\begin{tabular}{|l|l|}
\hline 11 & $\begin{array}{l}\text { Physical Environments } \\
\text { Influencing Bicyclists' } \\
\text { Perception of Comfort on } \\
\text { Separated and On-street } \\
\text { Bicycle Facilities }\end{array}$ \\
\hline
\end{tabular}

Western Transportation Institute
This study investigated how the lack of bicycle facilities, on-road bicycle facilities, and off-road bicycle facilities (typically multi-use trails) impacts the representation of women as bicyclists in Melbourne, Australia. Melbourne has a population of approximately 3.6 million. The authors concluded that when incorporating distances from where the counts were observed to the central business district, women preferred off-road bicycle facilities. Therefore, they concluded that the number of users will be influenced by the type of bicycle facilities provided (if a population has an approximately 50/50 representation of women/men, providing only on-road bicycle facilities is expected to attract few women bicyclists).

The authors of this study used a GIS-based, grid model to evaluate a number of factors to locate and prioritize locations for bicycle infrastructure investments in Montreal. The data was obtained from readily available sources including an online survey of bicyclists in Montreal, bicycle collision location data from an automobile insurance agency, and the Montreal Origin-Destination survey. Data on the following four factors was aggregated into 300-meter grid cells: (1) number of observed bicycle trips; (2) number of potential bicycle trips (any car trip less than $2 \mathrm{~km}$ ); (3) areas identified in bicyclist survey as needed infrastructure improvements; and (4) bicycle collision locations. The aggregated data was input into the "priority index," which weighed each factor equally. The priority index is mapped along with existing bicycle infrastructure. This allows for analysis of highpriority areas or areas that would benefit from infrastructure investment along with existing infrastructure.

This model provides a method to analyze multiple combinations of factors that may determine where to prioritize bicycle infrastructure in a community. The factors chosen for this study are just examples of the types of factors that could be considered, but an analyst must determine which factors are important for a specific community.

$\mathrm{Li}$ et al. evaluated the relationship between bicyclist level of comfort and physical environment factors. A field investigation of 14 on-street and 29 separated bicycle facilities was conducted in Nanjing, China. 1074 bicyclists were asked to rate their level of comfort from 1 (terrible) to 5 (excellent) on the facility they just rode. These comfort levels were evaluated with physical characteristics of the facility (slope, traffic levels, etc.). The study found that the following factors have an effect on a bicyclist's perceived 


\begin{tabular}{|c|c|c|c|}
\hline & $\begin{array}{l}\text { http://www.sciencedirect. } \\
\frac{\text { com/science/article/pii/S }}{\underline{1361920911001556}}\end{array}$ & $\begin{array}{l}\text { level of comfort. For separated bicycle facilities, the following factors had an impact on } \\
\text { comfort: (1) width of path; (2) slope; (3) bus stops; (4) pedestrian presence; and (5) } \\
\text { amount of bicycle traffic. For on-street bicycle facilities the following factors were } \\
\text { determined to affect comfort levels: (1) width of bike lane; (2) amount of bicycle traffic; } \\
\text { (3) slope; (4) bus stops; (5) automobile traffic; (6) on-street parking; and (7) electric } \\
\text { bicycle use. }\end{array}$ & \\
\hline 12 & $\begin{array}{l}\text { Cycling to work in } 90 \\
\text { large American cities: } \\
\text { new evidence on the role } \\
\text { of bike paths and lanes } \\
\text { https://link.springer.com/ } \\
\underline{\text { article/10.1007/s11116- }} \\
\underline{011-9355-8}\end{array}$ & $\begin{array}{l}\text { This article used data collected from } 90 \text { of the } 100 \text { largest U.S. cities. The authors applied } \\
\text { multiple model frameworks to the data and concluded that a Binary Logit Proportions } \\
\text { regression fit the best. The study found that cities with more bike paths and lanes were } \\
\text { associated with greater bike commuter rates. They also identified 1) safety, 2) lower } \\
\text { automobile ownership, 3) less sprawl, 4) higher gas prices, and 5) a larger proportion of } \\
\text { students in the city population to be associated with greater levels of bicycling to work. } \\
\text { Safety, as measured at the state level (there was no available data at the city level), was } \\
\text { found to be associated with greater levels of cycling to work. Lower auto ownership } \\
\text { (chosen instead of per capita income; the two were correlated so only one could be used) } \\
\text { was also found to be associated with greater levels of cycling to work. The authors also } \\
\text { found that more sprawl, defined by the composite sprawl index, was associated with lower } \\
\text { levels of cycling to work. The authors also used the average gasoline prices by state from } \\
\text { the Energy Information Administration for } 2006-2008 \text { and found that higher gas prices } \\
\text { are associated with higher levels of cycling to work. The results also showed that a city } \\
\text { with a greater proportion of students in the population had greater levels of cycling to } \\
\text { work. The authors also observed that cities in the western U.S. were found to have a } \\
\text { larger supply of bike paths per capita; the Midwest, South, and Northeast were grouped } \\
\text { with similar levels. They also noted that cycling is more common when it is viewed by } \\
\text { the population as a "normal" activity. }\end{array}$ & 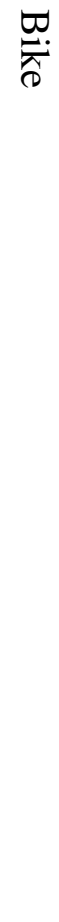 \\
\hline 13 & $\begin{array}{l}\text { Share the Road for a } \\
\text { Healthy Maine } \\
\text { http://www.pedbikeinfo. } \\
\text { org/data/library/details.cf } \\
\underline{\text { m?id=3966 }}\end{array}$ & $\begin{array}{l}\text { A Pedestrian and Bicycle Information Center (PBIC) Case Study, "Share the Road for a } \\
\text { Healthy Maine," provided information on a bicycle awareness campaign led by the } \\
\text { Bicycle Coalition of Maine (BCM). It noted that in the past, 1) bumper stickers, 2) driver } \\
\text { education instructor training, 3) additions to the Maine Motorist Handbook and Maine } \\
\text { Driver's Exam, and 4) providing general education at select venues had been executed } \\
\text { but had limited success on raising awareness. Funding from the National Highway } \\
\text { Transportation Safety Administration and the Maine Department of Transportation was }\end{array}$ & 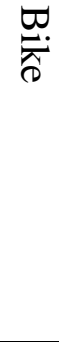 \\
\hline
\end{tabular}




\begin{tabular}{|c|c|c|c|}
\hline & & $\begin{array}{l}\text { provided for a two-year project. In May of 2006, } 115 \text { television ads, } 276 \text { radio spots, } 10 \\
\text { newspaper ads, and } 300,000 \text { online "impressions" were made in the Portland, Maine area. } \\
\text { While the intent of the original study was to evaluate the impacts, the evaluation portion } \\
\text { of the study was not achieved. However, BCM believed that the information learned from } \\
\text { the media blitz was valuable. }\end{array}$ & \\
\hline 14 & $\begin{array}{l}\text { Influence of Individual } \\
\text { Perceptions and Bicycle } \\
\text { Infrastructure on } \\
\text { Decision to Bike } \\
\underline{\text { http://trrjournalonline.trb. }} \\
\underline{\text { org/doi/abs/10.3141/214 }} \\
\underline{0-18}\end{array}$ & $\begin{array}{l}\text { Researchers used a web-based survey, deployed via university list-serves, to better } \\
\text { understand what influenced mode choice of commuters traveling to the University of } \\
\text { Maryland's campus. A total of } 1,627 \text { responses were received over } 20 \text { days in April of } \\
\text { 2008. The survey was promoted to both bicyclists and non-bicyclists, and the researchers } \\
\text { used categorical responses by survey respondents to categorize them as bicyclists or not. } \\
\text { Respondents who had bicycled within the last week, the last month, or the last year were } \\
\text { considered bicyclists. Approximately } 69 \% \text { of respondents were women, and the authors } \\
\text { did not indicate in their write-up whether or not their data was adjusted to account for the } \\
\text { bias towards a female response. The authors used a discrete choice model, where bicycle, } \\
\text { walk, public transportation, and driver were the four choices. The model suggested that } \\
\text { 1) flexibility in departure time, 2) one's perception of safety, and 3) cost of parking } \\
\text { influence a commuter's mode choice. }\end{array}$ & 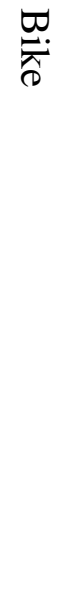 \\
\hline 15 & $\begin{array}{l}\text { The Rise of Bicycling in } \\
\text { Smaller and Midsize U.S. } \\
\text { Cities } \\
\text { https://www.citylab.com/ } \\
\text { transportation/2014/05/ri } \\
\text { se-bicycling-smaller-and- } \\
\text { midsize-us-cities/9059/ }\end{array}$ & $\begin{array}{l}\text { This document is provided via CityLab. It suggests that a benefit yet to be achieved by } \\
\text { smaller cities is their shorter trip distances and lower motor vehicle traffic volume. It also } \\
\text { notes that the top ten cities in the U.S. for bike commuters have populations less than } \\
\text { 250,000 (Davis, CA; Boulder, CO; Palo Alto, CA; Eugene, OR; Cambridge, MA; Fort } \\
\text { Collins, CO; Berkeley, CA; Santa Barbara, CA; Madison, WI; and Missoula, MT). It } \\
\text { suggests that while men are the dominant bicyclists at present, traffic-protected cycle } \\
\text { tracks could help attract other underrepresented groups (women, children, elderly). The } \\
\text { authors also suggest that implementing traffic calming in neighborhoods by restricting } \\
\text { through traffic and reducing speeds can create more bicycle friendly environments. }\end{array}$ & 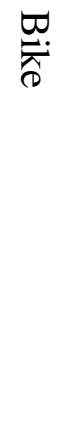 \\
\hline
\end{tabular}


16 Factors associated with proportions and miles of bicycling transportation for recreation in six small US cities

http://www.sciencedirect. com/science/article/pii/S 1361920909001126
This study wanted to understand factors affecting bicycling for transportation and recreation. The six small cities included in the study were from the western part of the U.S.: Davis (68,111 people), Woodland (55,468 people), Chico (91,567 people), and Turlock (72,796 people), California; Eugene (166,575 people), Oregon; and Boulder (97,948 people), Colorado. The researchers sent out 1500 hard copy surveys to potential respondents in each of the cities. The authors employed a binary logit model to compare the outcomes based on 1) individual factors, 2) physical environmental factors, and 3) social environmental factors. One of the most significant findings of their study that is relevant to the study at hand is an indirect link between the perception of safety and the presence of bicycle infrastructure.

17 The Societal Costs and Benefits of Commuter Bicycling: Simulating the Effects of Specific Policies Using System Dynamics Modeling

https://ehp.niehs.nih.gov/ 1307250/

18 Determinants of bicycle use: do municipal policies matter?

http://www.sciencedirect. com/science/article/pii/S $\underline{0965856404000382}$ municipal policies do have an influence on modal choice over short distances (less than
The researchers used system dynamics modeling (SDM) to investigate the impacts that various policies might have on bicycle commuting in a car-dominated city. Auckland, New Zealand was used as the case study. The perception that bicycling is tightly tied to injury and death was found to significantly impact a person's interest in bicycling. They found that the regional cycling network, which is the current policy, will result in a limited mode share shift from driving to bicycling. The authors also found that physical separation would result in the largest mode shift, which related to safety concerns.

This research effort examines the extent to which municipality policies affect variations in bicycle use between municipalities within the Netherlands. The study found that $7.5 \mathrm{~km})$. Specifically, the project found that inter-municipality variation in bicycle use is related to the following physical aspects - altitude differences (slopes) and city size (medium size cities have more bike use, generally), and age groups of population (youngster $=12-16 \mathrm{yrs}$ and young adults 16-22 yrs most frequent use); differences in ethnic composition and cultural traditions; and the following policy-related variables number of stops on a route for cyclists, hindrances of road use, and safety; the relative position of bicycles to car, car speed, and parking costs. Travel time is also an important determinant of travel demand (direct routes and a few number of stops). 


\begin{tabular}{|l|l|}
\hline & $\begin{array}{l}\text { The study suggests municipalities can utilize active price-setting for parking cars to adapt } \\
\text { the spatial organization of cities (e.g., encourage bike use but charging more for parking } \\
\text { in certain areas). Bicycle use can be encouraged by making it more appealing through } \\
\text { reduced costs, or making driving more expensive than biking. } \\
\text { The study suggests that bicyclist safety and satisfaction are related to policies - from } \\
\text { politicians and maintenance of infrastructure, as well as individual behaviors. } \\
\text { This work indicates "that the low accident rates experienced by cyclists in a small town } \\
\text { do matter, explaining their modal choice." The study suggests that directly including } \\
\text { ethnic background in travel surveys would enable researchers to better understand } \\
\text { variations in bicycle use as it relates to cultural traditions. }\end{array}$ \\
\hline
\end{tabular}




\section{REFERENCES}

Adams, P. (2018, June). Regional Transportation Planner. (N. Villwock-Witte, Interviewer)

Alta Planning + Design, Small Urban and Rural Livability Center - Western Transportation Institute, National Association of Counties. (2016). Small Towns and Rural Multimodal Networks. Washington, DC: Federal Highway Administration (FHWA).

Andersen, M. (2017, August 24). One of the Most Important Parts of Bike Infrastructure is Invisible. peopleforbikes. Retrieved May 2, 2018, from https://peopleforbikes.org/blog/one-of-the-most-important-parts-of-bike-infrastructure-isinvisible/

Buehler, R., \& Pucher, J. (2012). Cycling to work in 90 large American cities: new evidence on the role of bike paths and lanes. Transportation, 39, 409-432.

Buehler, R., \& Pucher, J. (2014). The Rise of Bicycling in Smaller and Midsize U.S. Cities. Citylab. Retrieved 2017, from https://www.citylab.com/transportation/2014/05/risebicycling-smaller-and-midsize-us-cities/9059

Cervero, R., Sarmiento, O., Jacoby, E., Fernando Gomez, L., \& Neiman, A. (2009). Influences of Built Environments on Walking and Cycling: Lessons from Bogota. International Journal of Sustainable Transportation, 203-226.

Colville-Andersen, M. (2018). CopenHagenize: The Definitive Guide to Global Bicycle Urbanism. Washington DC: Island Press.

Colvin, M., Pedroso, M., \& Mennesson, M. (2014). Safe Routes to School: How States are Adapting to a New Legislative Framework. Robert Wood Johnson Foundation.

Garrard, J., Rose, G., \& Lo, S. (2008). Promoting transportation cycling for women: The role of bicycle infrastructure. Preventive Medicine, 46, 55-59.

Hemken, K., Elder, J., Hoffe, A., Lammle, E., Stauner, D., London, J., . . . Quisberg, J. (2011). Complete Streets Policy: City of New Hope. New Hope: City of New Hope.

KTU+A Planning and Landscape Architecture, Ryan Snyder Associates, U.S. Department of Housing and Urban Development. (2014). Creating Walkable \& Bikeable Communities. Washington, DC: U.S. Department of Housing and Urban Development.

Langdon, P. (2017). Within Walking Distance: Creating Livable Communities for All. Washington, D.C.: Island Press. Retrieved April 30, 2018, from https://islandpress.org/book/withinwalking-distance

Li, H., Cebe, J., Khoeini, S., Xu, Y., Dyess, C., \& Guensler, R. (2018). A Semi-Automated Method to Generate GIS-Based Sidewalk Networks for Asset Management and Pedestrian Accessibility Assessment. Transportation Research Record: Journal of the Transportation Research Board, 1-9.

Macmillan, A., Connor, J., Witten, K., Kearns, R., Rees, D., \& Woodward, A. (2014). The Societal Costs and Benefits of Commuter Bicycling: Simulating the Effects of Specific Policies Using System Dynamics Modeling. Environmental Health Perspectives, 122(4), 335-344. Retrieved from https://ehp.niehs.nih.gov/1307250/ 
Miranda-Moreno, L. F., Morency, P., \& El-Geneidy, A. M. (2011). The link between built environment, pedestrian activity and pedestrian-vehicle collision occurrence at signalized intersections. Accident Analysis and Prevention, 43, 1624-1634.

National Park Service, U.S. Department of Interior. (n.d.). National Register of Historic Places Program: Frequently Asked Questions. Retrieved July 23, 2018, from National Park Service: https://www.nps.gov/nr/faq.htm

National Transportation Safety Board (NTSB). (2017). Reducing Speeding-Related Crashes Involving Passenger Vehicles. Washington, D.C.: NTSB.

Peters, A. (2014, August 15). Retrieved October 16, 2017, from The Cities That Spend The Most On Bike Lanes Later Reap The Most Reward: https://www.fastcompany.com/3034354/the-cities-that-spend-the-most-on-bike-laneslater-reap-the-most-reward

Riccardi, N. (2017, December 3). Utah's Tenacious Efforts to Take Back Federal Land Stand Out. Retrieved from U.S. News \& World Report: https://www.usnews.com/news/beststates/utah/articles/2017-12-03/utah-stands-out-for-its-extreme-stance-against-federallands

Ruiz, R., \& Perna, L. W. (2017, June 19). Geography and College Attainment: A Place-Based Approach. Retrieved June 6, 2018, from Higher Education Today: https://www.higheredtoday.org/2017/06/19/geography-college-attainment-place-basedapproach/

Schmitt, A. (2016, May 31). 3 Graphs That Explain Why 20 MPH Should Be the Limit on City Streets. $\quad$ StreetsBlogUSA. Retrieved May 3, 2018, from https://usa.streetsblog.org/2016/05/31/3-graphs-that-explain-why-20-mph-should-be-thelimit-on-city-streets/

The League of American Wheelmen, Inc. (n.d.). Award Database. Retrieved June 11, 2018, from The League of American Bicyclists: http://bikeleague.org/bfa/awards\#community

Villwock-Witte, N. (2018). Analysis of Minnesota Communities with Less Than 10,000 People. Bozeman: Western Transportation Institute at Montana State University.

Villwock-Witte, N. (2018). Local Agency Interviews. Bozeman: Western Transportation Institute at Montana State University. Retrieved from https://westerntransportationinstitute.org/research_projects/bicycle-and-pedestrianinfrastructure-improvements-realized-in-communities-of-less-than-10000/

Villwock-Witte, N. (2018). Synthesis of Findings. Bozeman: Western Transportation Institute at Montana State University. Retrieved from https://westerntransportationinstitute.org/research_projects/bicycle-and-pedestrianinfrastructure-improvements-realized-in-communities-of-less-than-10000/

Villwock-Witte, N., \& Clouser, K. (2016). Mobiity Mindset of Millennials in Small Urban and Rural Areas. Bozeman: Western Transportation Institute at Montana State University. Retrieved from http://surlc.org/2015/01/01/mobility-mindset-of-millennials-in-smallurban-and-rural-areas/ 
Villwock-Witte, N., \& Leidekker, J. R. (2015). White Bikes of De Hoge Veluwe National Park, Netherlands: Case Study for Consideration by U.S. Federal Land Managers. Transportation Research Record(2499), 33-39. Retrieved April 17, 2107, from http://trrjournalonline.trb.org/doi/abs/10.3141/2499-05

Villwock-Witte, N., Gleason, R., \& Shapiro, P. (2011). Good Practices to Encourage Bicycling \& Pedestrians on Federal Lands. Bozeman: Paul S. Sarbanes Transit in Parks Technical Assistance Center (TRIPTAC).

Xing, Y., Handy, S. L., \& Mokhtarian, P. L. (2010). Factors associated with proportions and miles of bicycling for transportation and recreation in six small US cities. Transportation Research Part D, 15, 73-81. Retrieved from http://www.sciencedirect.com/science/article/pii/S1361920909001126 